\title{
A Multisensor Comparison of Ocean Wave Frequency Spectra from a Research Vessel during the Southern Ocean Gas Exchange Experiment
}

\author{
Alejandro Cifuentes-LOREnZEN AND JAMES B. EDSON \\ Department of Marine Sciences, University of Connecticut, Groton, Connecticut \\ CHRISTOPHER J. ZAPPA \\ Lamont-Doherty Earth Observatory, University of Columbia, Palisades, New York \\ LUDOVIC BARITEAU \\ Cooperative Institute for Research in Environmental Sciences, University of Colorado Boulder, Boulder, Colorado
}

(Manuscript received 22 August 2012, in final form 15 July 2013)

\begin{abstract}
Obtaining accurate measurements of wave statistics from research vessels remains a challenge due to the platform motion. One principal correction is the removal of ship heave and Doppler effects from point measurements. Here, open-ocean wave measurements were collected using a laser altimeter, a Doppler radar microwave sensor, a radar-based system, and inertial measurement units. Multiple instruments were deployed to capture the low- and high-frequency sea surface displacements. Doppler and motion correction algorithms were applied to obtain a full $1 \mathrm{D}(0.035-1.3 \pm 0.2 \mathrm{~Hz})$ wave spectrum. The radar-based system combined with the laser altimeter provided the optimal low- and high-frequency combination, producing a frequency spectrum in the range from 0.035 to $1.2 \mathrm{~Hz}$ for cruising speeds $\leq 3 \mathrm{~m} \mathrm{~s}^{-1}$ with a spectral rolloff of $f^{-4} \mathrm{~Hz}$ and noise floor of $-20 /-30 \mathrm{~dB}$. While on station, the significant wave height estimates were comparable within $10 \%-15 \%$ among instrumentation. Discrepancies in the total energy and in the spectral shape between instruments arise when the ship is in motion. These differences can be quantified using the spectral behavior of the measurements, accounting for aliasing and Doppler corrections. The inertial sensors provided information on the amplitude of the ship's modulation transfer function, which was estimated to be $\sim 1.3 \pm 0.2$ while on station and increased while underway [2.1 at ship-over-ground (SOG) speed; $\left.4.3 \mathrm{~m} \mathrm{~s}^{-1}\right]$. The correction scheme presented here is adequate for measurements collected at cruising speeds of $3 \mathrm{~m} \mathrm{~s}^{-1}$ or less. At speeds greater than $5 \mathrm{~m} \mathrm{~s}^{-1}$, the motion and Doppler corrections are not sufficient to correct the observed spectral degradation.
\end{abstract}

\section{Introduction}

Comprehensive wave field measurements (i.e., wave spectra) serve both a practical and scientific purpose. Navigational systems rely on the capacity to obtain and incorporate wave field information into route-choosing routines. The efficiency and effectiveness of naval operations (e.g., Nielsen 2006; Thornhill and Stredulinsky 2010) improve with direct measurements of wave field statistics (i.e., the spectrum of the sea surface displacement) (e.g., Nielsen 2006; Tannuri et al. 2003; Toshio and

Corresponding author address: A. Cifuentes-Lorenzen, University of Connecticut, 1080 Shennecossett Rd., Groton, CT 06340. E-mail: alejandro.cifuentes@uconn.edu
Daisuke 2002). From a scientific perspective, wave field measurements are highly relevant to investigations of air-sea interaction, climate modeling, and weather forecasting, whereby observations are required in order to further develop the existing theory. These investigations require careful tracking of a ship's response to the wave field in order to remove the wave-induced motion (i.e., motion contamination) from oceanic and atmospheric measurements (e.g., from sonic anemometers, $\mathrm{CO}_{2}$ sensors, and hygrometers) (e.g., Edson et al. 1998; Miller et al. 2008).

The wave-induced motion, or motion contamination, can significantly alter the signal collected by instrumentation deployed on the ship. There are several sources of motion contamination, but the largest contributors 
include angular and vertical accelerations of the ship and the Doppler effects while the ship is underway. The issue of motion contamination in air-sea flux measurements and wave field statistics is often mitigated by deploying instrumentation on buoys, for which the wave-induced motion is assumed to be a direct response of the wave field (e.g., pitch/roll buoy measuring the vertical acceleration and the slope of the sea surface). Nonetheless, the deployment, retrieval, and maintenance of buoy systems are costly and add operational complications to the field campaign. In the open ocean, where sea spray, severe wave-induced motion, and wave breaking are commonplace, the durability and stability of instruments on a long-term deployment are a challenge to achieve.

Buoy- and ship-based deployment alternatives, such as aircraft platforms, have successfully provided directional wave spectra over relatively short periods of time in coastal regions using an array of laser altimeters (e.g., Hwang et al. 2000; Sun et al. 2005). However, the aircraft approach is costly and is also subject to both Doppler and motion contamination and it only allows sampling over short time periods. Fixed platforms, which are unaffected by wave motion and are easy to service and monitor, represent the ideal deployment strategy (e.g., Irish et al. 2006; Edson et al. 2007). However, fixed platforms clearly limit the spatial extent of measurements and are only a viable option in coastal regions to date.

Ultimately, under open-ocean conditions, shipborne measurements, where instruments are easily mounted, monitored, and transported, become a viable deployment strategy if adequate motion contamination correction schemes can be applied and the limitations of the instrumentation deployed are well characterized. Several previously published papers identify the strengths and limitations of different sensors measuring the same parameter. For example, X-band wave radars [i.e., the Wave and Surface Current Monitoring System, (WaMoS)] provide reasonably accurate wave direction and spectral peak characteristics but often inaccurate wave heights (Stredulinsky and Thornhill 2011). Nonetheless, Dankert and Rosenthal (2004) and Nieto Borge et al. (2004) suggest that WaMoS, which is engineered to analyze backscatter signatures (visible as "sea clutter" on the radar), not only provides accurate directional spectral information (i.e., peak phase speed, frequency, wave direction, and period) but also consistent significant wave heights when compared to buoy observations. Despite this agreement, values of significant wave height produced by WaMoS while mounted on a ship have also been shown to be consistently lower than observations made on a wave buoy (Stredulinsky and Thornhill 2011; Thornhill and Stredulinsky 2010). Stredulinsky and Thornhill (2011) proposed a shipboard wave data fusion
(SWDF) algorithm in order to improve the wave height measurements produced by the WaMoS system. The SWDF uses the response of the ship for the signal-tonoise ratio as a basis for scaling the directional wave spectra. This modifies the modulation transfer function (MTF) used in the inverse problem of retrieving the wave field spectrum from the 3D image provided by the wave radar. A full assessment of the MTF is beyond the scope of this paper; however, the magnitude of the MTF is approximated by combining the ship's response (output) at its center mass (ship-CM), based on the inertial measurement units (IMUs) sensors' projection and the sea surface displacement estimates from the laser altimeter and Doppler radar measurements after motion correction (input). The spectral relation between the input and output is used to generate the empirical transfer function estimator (ETFE) that is used to track and explore the ship's response to the wave field.

Here, we perform an instrument intercomparison to resolve discrepancies between instruments, to apply correction routines when possible, and to identify platform-defined operating conditions [i.e., ship-overground (SOG) speeds] under which a ship-based deployment strategy will or will not be successful. The total spectral energy, spectral peak and shape information (including the tail behavior), and significant wave heights resolved here are tested over a large range of forcing conditions in order to constrain the strength and limitations of each instrument. We incorporate the ship's three characteristic responses in the vertical plane (i.e., heave, roll, and pitch) into the Edson et al. (1998) motion correction algorithm in order to remove the wave-induced oscillations from oceanographic and atmospheric measurements with the goal of providing accurate 1D frequency spectra over the widest possible frequency range for the open ocean.

\section{Methodology}

Atmospheric and oceanic measurements were collected during the Southern Ocean Gas Exchange Experiment (SOGasEx, March-April 2008) on board the National Oceanic and Atmospheric Administration (NOAA) ship the research vessel (R/V) Ronald H. Brown in the Atlantic sector of the Southern Ocean. The primary objective of SOGasEx was to investigate the processes governing gas exchange under high wind conditions by implementing the dual tracer (Ho et al. 2011) and the direct covariance techniques (Edson et al. 2011). The atmospheric instrumentation was deployed on the jack staff of the ship, located at $18 \mathrm{~m}$ above the mean sea surface (Fig. 1). Three Gill R-3 sonic anemometers were deployed to measure the wind speed $\left(U_{10}\right)$ and the 


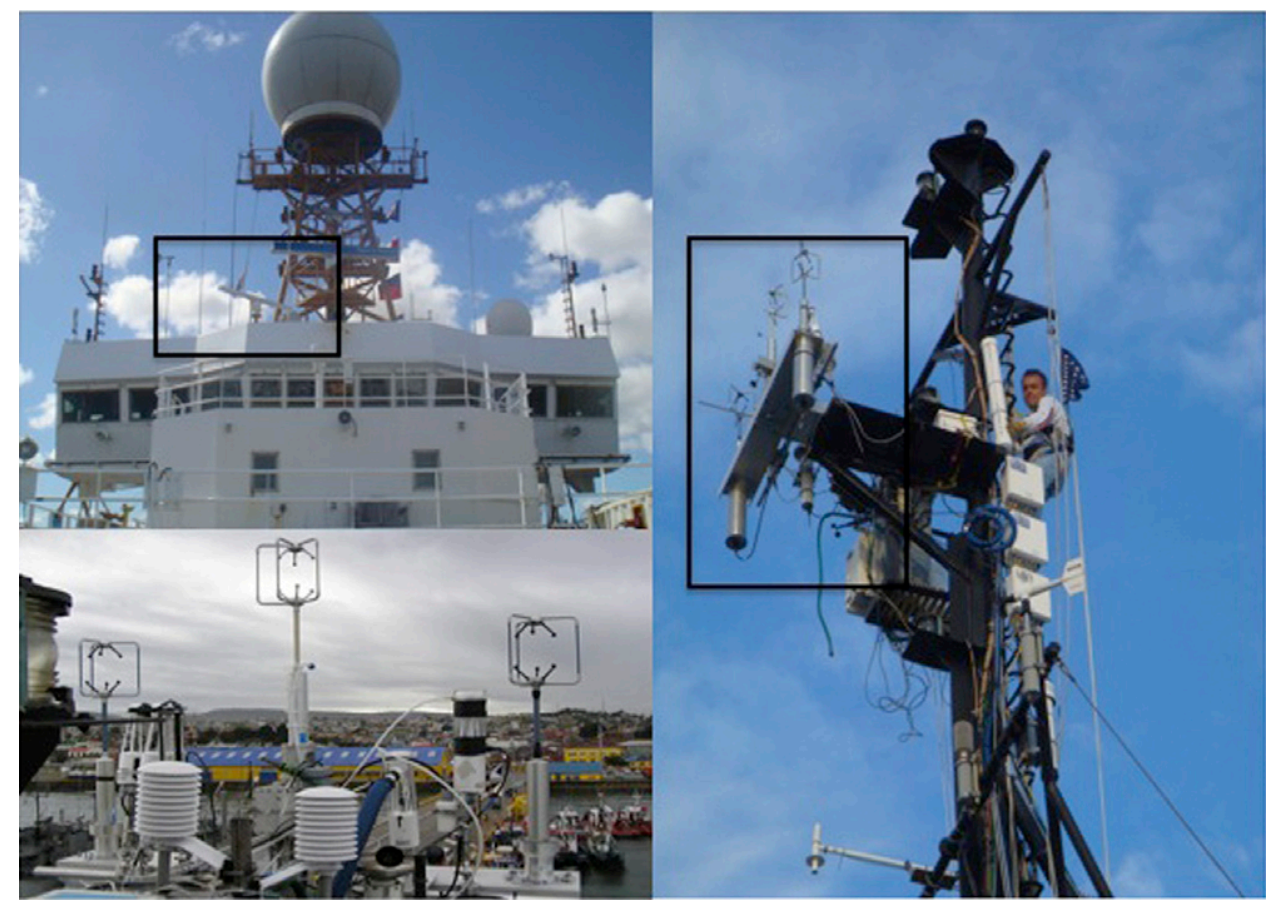

FIG. 1. (top left) The flying bridge of the R/V Ronald H. Brown, equipped with the Furuno 1510 radar (from the WaMoS system). (bottom left) The flux package, which contained all of the sensors that collected atmospheric measurements, was deployed on top of the mast ( $18 \mathrm{~m}$ above the mean sea surface). (right) The jack staff of the research vessel was outfitted with three sonic anemometers and two IMUs (black box).

turbulent perturbations of velocity and temperature. Here, $U_{10}$ is the wind speed adjusted to a height of $10 \mathrm{~m}$ and neutral atmospheric stability using Monin-Obukov similarity theory (Fairall et al. 1996). High-frequency humidity and $\mathrm{CO}_{2}$ measurements were collected using the LI-7500 infrared absorption hygrometers (Licors). Two sets of IMUs were deployed directly underneath the sonic anemometers to correct the measurements for motion contamination following Edson et al. (1998) (right panel, Fig. 1). The WaMoS, the Riegl laser altimeter, and Tsurumi-Seiki Co., Ltd (TSK) Doppler radar were used to measure the wave frequency spectrum from 0.035 to $1.2 \mathrm{~Hz}$ while underway and from 0.035 to $1.5 \mathrm{~Hz}$ while on station. These systems were deployed on the flying bridge, the jack staff (at $10 \mathrm{~m}$ above mean sea level) and the outboard of the bow, respectively. Details on the wave field instrumentation can be found in section $2 \mathrm{a}$ below.

\section{a. Instrumentation}

\section{1) INERTIAL MOTION UNITS AND THE MOTION CORRECTION ALGORITHM FOR SHIP HEAVE}

The IMUs (Systron Donner MotionPak 6-variable) consist of three orthogonal linear accelerometers and angular rate sensors, measuring at a resolution of $<10 \mu \mathrm{g}$, and $<0.004^{\circ} \mathrm{s}^{-1}$, respectively. The IMUs provide highfrequency measurements of accelerations and platform tilt, which constitute the basis of the motion correction algorithm (Edson et al. 1998). The velocities and accelerations from the IMUs were used to correct the laser altimeter and the Doppler radar measurements collected at different heights. The accelerometers provided the ship's response to the wave field and were used in a shipas-buoy analogy to retrieve a low-frequency wave spectrum (Thornhill and Stredulinsky 2010). The fundamental input was a set of response measurements (i.e., pitch, roll, and yaw) of the ship's motion component. Here, the ship's response was assumed to be linear; therefore, no second-order pitch-roll/roll-pitch interaction was accounted for. The observed measurement was transformed from the platform frame of reference, where $\phi_{\text {obs }}$ is the roll, $\theta_{\text {obs }}$ is the pitch, and $\psi_{\text {obs }}$ is the yaw of the ship, to a fixed frame of reference.

Angular rates were corrected by adding the slow angles (low frequency, low-pass filtered) to the fast angles (high frequency, high-pass filtered). The slow angles, including pitch-low (pivot along port-starboard, $y$ axis), roll-low (pivot along the stern-bow, $x$ axis), and yaw-low (pivoting along the vertical, $z$ axis), were obtained by 


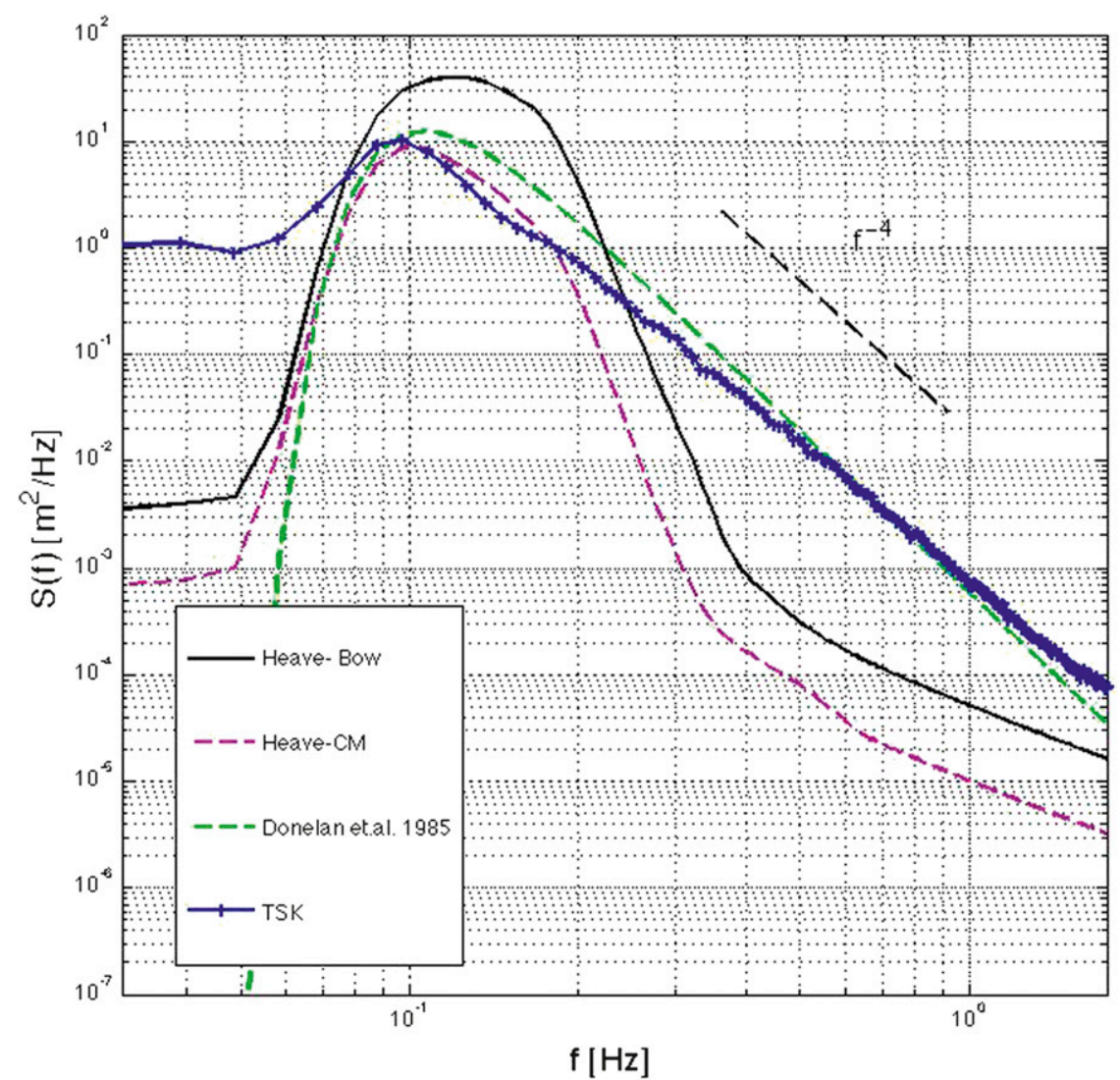

FIG. 2. The heave correction for $1<\mathrm{SOG}<3 \mathrm{~m} \mathrm{~s}^{-1}$ and a $\left\langle U_{10}\right\rangle=11.2 \mathrm{~m} \mathrm{~s}^{-1}$. All averaged spectra are based on 110 realizations of $30 \mathrm{~min}$ each. Spectral density functions for heave at the bow of the ship used to motion correct the Riegl and TSK data (heave-bow). Also included is the heave measured at the ship's center of mass (heave-CM), which provides an independent wave field measurement for low frequencies and an assessment of the ship's response to the wave field. The Donelan et al. (1985) parameterization acts as a reference.

applying a low pass to the signal retrieved by the accelerometers. Low-frequency sensor drift was removed using a Butterworth high-pass filter. Attenuation in the stopband was set to $25 \mathrm{~dB}$ and the passband was set so that no more than $10 \mathrm{~dB}$ was lost. A digital filter of order five with a natural frequency of $0.0041 \mathrm{~Hz}$ resulted. The low-frequency cutoff was defined as $1 / 30 \mathrm{~Hz}$.

The angular velocities $\mathbf{V}_{\mathbf{r}}(\mathbf{t})$ were required to calculate corrected velocities and displacements in a fixed frame of reference following

$$
\mathbf{V}_{\mathbf{r}}(\mathbf{t})=\boldsymbol{\Omega}_{\mathrm{obs}} \times \mathbf{R}
$$

where $\boldsymbol{\Omega}_{\text {obs }}$ is the observed angular rate vector and $\mathbf{R}$ is the vector between the motion pack and the instrument (in meters). For the estimation of wave field statistics using the ship-as-buoy analogy, the vector $\mathbf{R}$ is used to extrapolate the linear accelerations and angular velocities at the IMU height $(18 \mathrm{~m})$ on the bow to the ship's center of mass $(\mathrm{CM})$.
For example, to correct the Doppler radar, $\mathbf{R}$ gives the heave of the ship at the bow and is the distance between

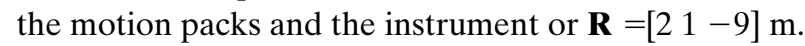

Likewise, to retrieve sea surface displacement using the ship as a wave follower, the distance between the IMU and the CM was $\mathbf{R}=\left[\begin{array}{lll}42.5 & 0 & -18\end{array}\right] \mathrm{m}$. In all cases, the amplitude of the displacement at the bow was expected to be larger than the displacement at the CM. Heave at the CM in an AGOR-25 class vessel (i.e., the R/V Ronald H. Brown), measuring roughly $90 \mathrm{~m}(270 \mathrm{ft})$ in length, is expected to capture waves approximately $180 \mathrm{~m}$ in length $(\lambda)$, twice the length of the ship. Ships of this size have large inertia, ultimately filtering highfrequency wave components and reducing the frequency range of the spectrum that can be estimated using the ship-as-buoy analogy (e.g., Tannuri et al. 2003). According to the deep water wave dispersion relationship, a wavelength of $180 \mathrm{~m}$ corresponds to waves with a period of approximately $T \sim 10 \mathrm{~s}$. Once the accelerometers are projected into the $\mathrm{CM}$, the ship's response can be 

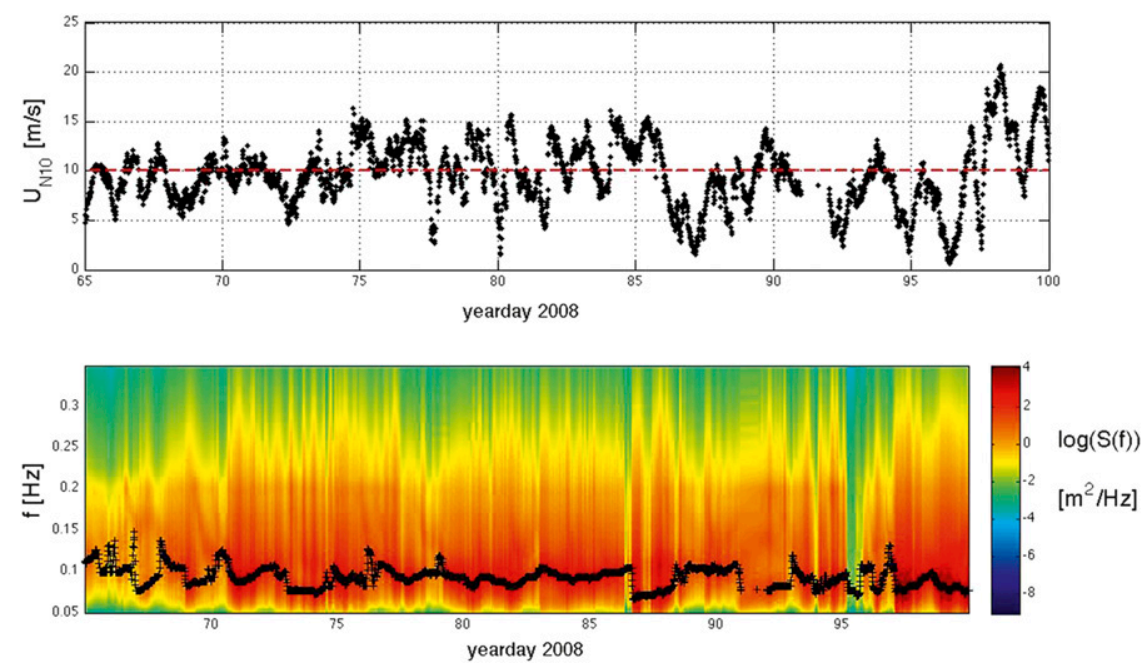

FIG. 3. (top) Neutral wind speed at $10 \mathrm{~m}$ ( $U_{10}$, black dots) as a function of yearday. A reference line is included at $U_{10}=10 \mathrm{~m} \mathrm{~s}^{-1}$ (red dots). (bottom) WaMoS-resolved frequency spectra $\log [S(f)]$ and the peak frequency of the wave field (black dots) for the SOGasEx cruise.

used to track the low-frequency range of the waves from 0.05 to $0.2 \mathrm{~Hz}$ (Fig. 2).

Sea surface displacement was estimated from the height of the ocean surface relative to the mean sea level using the Riegl and TSK measurements after accounting for the ship heave at the bow relative to the mean sea level following
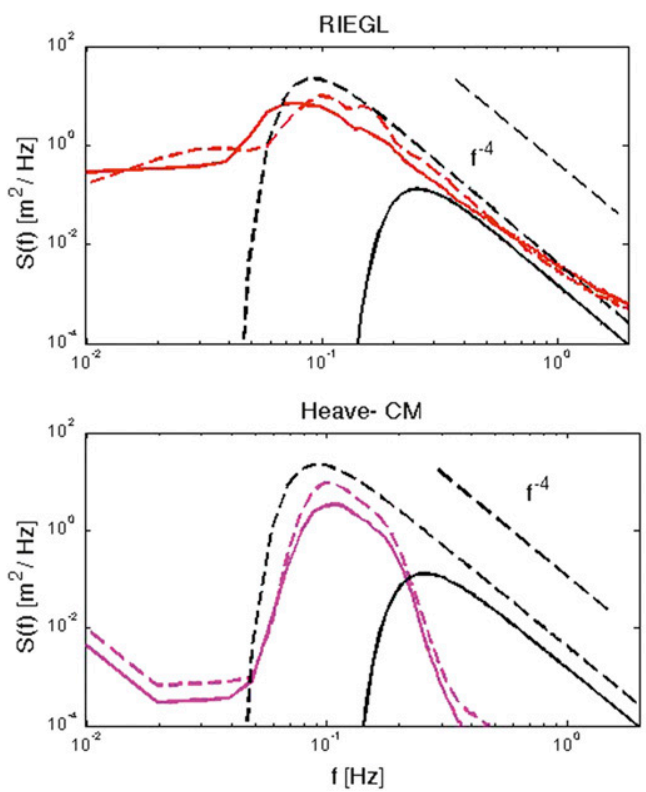

$$
\eta_{c}(t)=\eta_{i}(t)+h_{b}(t)
$$

where $\eta_{c}(t) \mathrm{m}$ is the corrected mean sea surface displacement (i.e., heave corrected), $\eta_{i}(t) \mathrm{m}$ is the total instrument displacement, and $h_{b}(t)$ is the heave of the ship at the bow based on the integrated vertical acceleration of the platform.
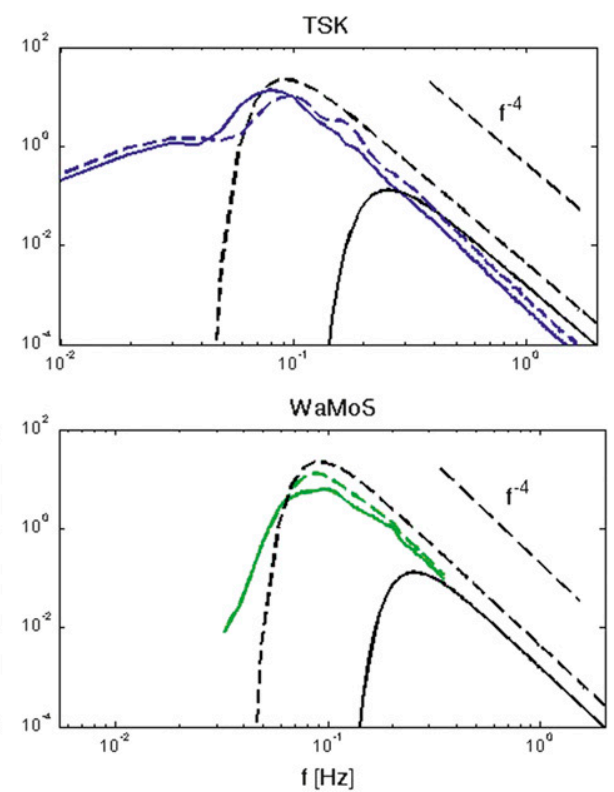

FIG. 4. Representative spectra $(0.02-2 \mathrm{~Hz})$ from the Riegl, TSK, WaMoS, and the ship-CM under different winds conditions, including low wind $U_{10}=5.1 \mathrm{~m} \mathrm{~s}^{-1}$ (solid lines) and high wind $U_{10}=$ $14.0 \mathrm{~m} \mathrm{~s}^{-1}$ (dashed lines). The low and high wind scenarios includes 22 and 130 spectral realizations (using a 30-min average), respectively. The high wind scenario corresponds to 130 spectral realizations of $30 \mathrm{~min}$. The Donelan et al. (1985) parameterization for both high (dashed black line) and low (solid black line) wind scenarios is included. For reference, the $f^{-4}$ frequency slope is also included (black dashed line). 


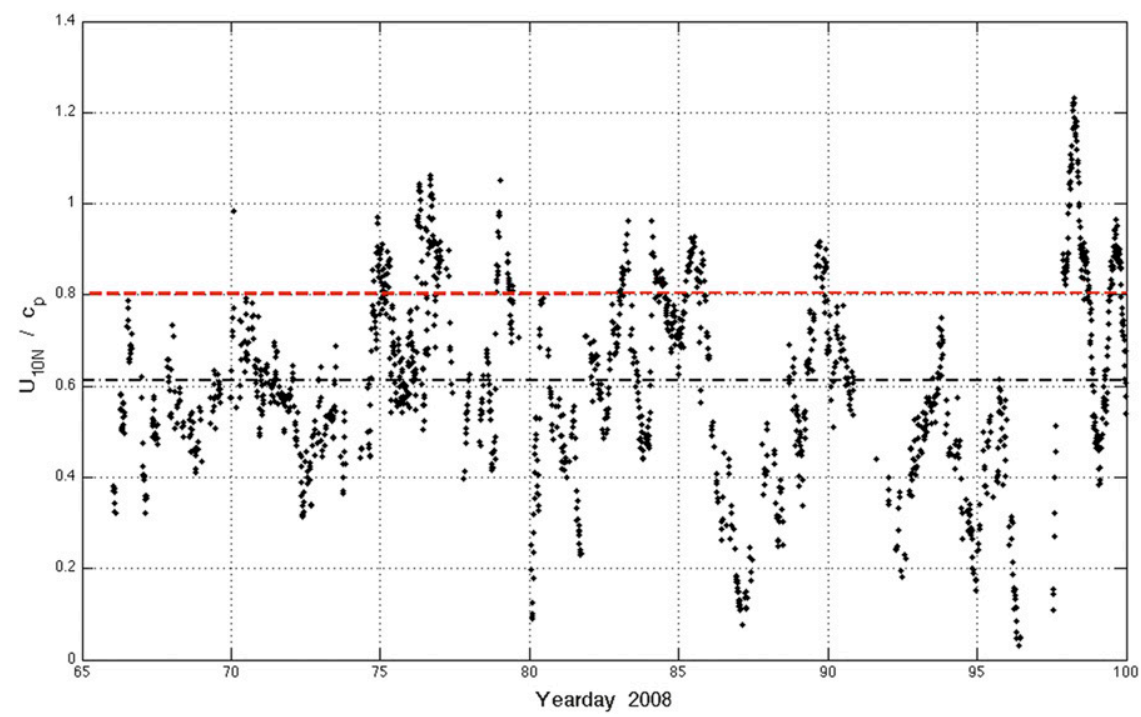

FIG. 5. Inverse wave age $\left(U_{10} / c_{p}\right)$, or "wind forcing," as a function of yearday during the SOGaSEx cruise (black dots). The threshold for developed seas is $c_{p} / U_{10} \sim 1.2$ or $U_{10} / c_{p} \sim 0.82$ (red dashed line). The mean of the SOGasEx times series was $\left\langle c_{p} / U_{10}\right\rangle=0.61$ (black dashed line).

\section{2) Wave And Current Monitoring System (WAMOS II)}

The WaMoS system (OceanWaveS GmbH) uses a marine navigation X-band radar (Furuno 1510 Mark 3) operating at $9.41 \mathrm{GHz}$ with an antenna rotation period of $1.5 \mathrm{~s}$ to measure sea surface anomalies and to produce a three-dimensional image of the wave field (Nieto
Borge and Soares 2000; Dankert and Rosenthal 2004). Directional wavenumber and frequency spectra were obtained from the 3D image by applying a Fast Fourier Transform (FFT). A brief description of the signal processing required for the image inversion is included here, however greater detail can be found in Nieto Borge et al. $(1999,2004)$ and Serafino et al. (2010).
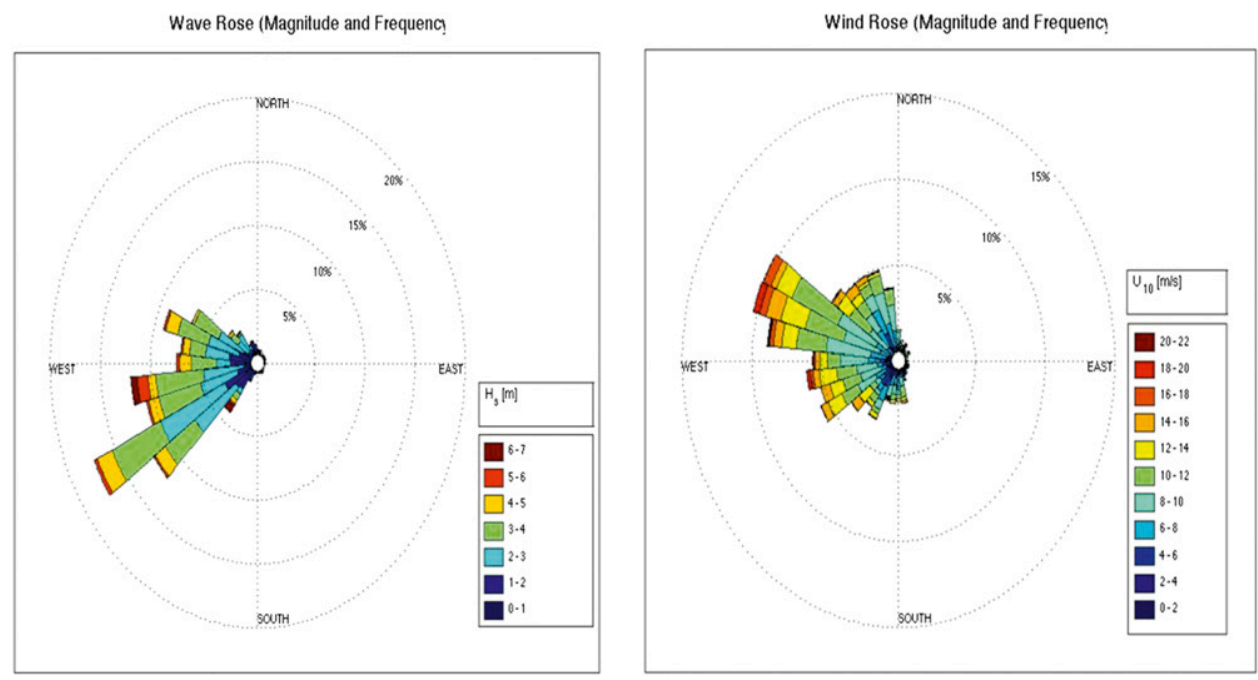

FIG. 6. (left) Peak wave direction, obtained using WaMoS, and intensity (following meteorological convention) represented in terms of the significant height $H_{s} \mathrm{~m}$. (right) Neutral wind information, including direction and intensity $\left(U_{10} \mathrm{~m} \mathrm{~s}^{-1}\right)$, measured using the flux system deployed on the jack staff of the R/V Ronald H. Brown. 
Directional wavenumber and frequency spectra were derived from the sequence of WaMoS radar digital images by first applying a Cartesian transform to the polar coordinate analysis area $\left(2 \mathrm{~km}^{2}\right)$ and then applying a discrete Fourier transform (Reichert et al. 1999). The WaMoS software applies corrections for shadowing and tilt modulation, which affect the backscattering of microwave radiation (Bragg scattering), but does not correct for hydrodynamic modulation. Further details on the modulation transfer function and bandpass filtering can be found in Reichert et al. (1999), Nieto Borge et al. (1999), and Nieto Borge et al. (2004).

A time series of directional wave spectra in the 0.035 $0.35-\mathrm{Hz}$ range with frequency and wavenumber resolution of $\delta f=0.005 \mathrm{~Hz}$ and $0.005 \mathrm{rad} \mathrm{m}^{-1}$ were produced from the data collected by the WaMoS system (bottom panel, Fig. 3). From spectral estimates, WaMoS also provided measurements of significant wave height (resolution of $\pm 0.5 \mathrm{~m}$ ), within a range of $0.5-20 \mathrm{~m}$, and the surface current speed $\left(U_{s} \mathrm{~m} \mathrm{~s}^{-1}\right)$. Surface current speed and direction was obtained by the internal signal processing algorithm in the WaMoS software. This followed from minimizing the distance between the position of the measured spectral energy in the 3D image spectrum and its position given by the dispersion relation for linear gravity waves (i.e., $\omega^{2}=g k$ ). The $\mathrm{WaMoS}$ measurements of surface current speed and direction were used in the Doppler correction routine (section 3a). The directional spectra provided by WaMoS was integrated over $\theta$ to generate $1 \mathrm{D}$ frequency spectra for a direct comparison to the Riegl laser altimeter and the TSK surface wave height meter point measurements and to the spectral information derived from the ship's response (Ship-CM) measured using the IMUs.

\section{3) Riegl LD90: LASER ALTIMETER}

A Riegl LD90-3800VHS laser altimeter (operation wavelength $\lambda=0.9 \mu \mathrm{m}$ with a beam divergence of $2.7-\mathrm{m} \mathrm{rad}$ ) was used to measure the distance to the wave field with a footprint of $2.65 \mathrm{~cm}$ in diameter at a range of $10 \mathrm{~m}$, resolving a frequency up to $5.4 \mathrm{~Hz}$. The instrument was deployed such that the angle of incidence was approximately $15^{\circ}$ in order to clear the bow of ship, where the ship's design water line was $5.2 \mathrm{~m}$. This sets the Riegl beam $7.85 \mathrm{~m}$ in front of the waterline with the lowest incidence angle possible in order to maximize the signal. Internal processing provided a $10-\mathrm{Hz}$ sampling frequency. The laser altimeter-derived distance to the wave field, once corrected for ship heave, produced a time series of mean sea surface displacement $\eta(t) \mathrm{m}$. Ultimately, the $1 \mathrm{D}$ frequency spectrum was resolved by applying an fast Fourier transform (FFT) to the signal.

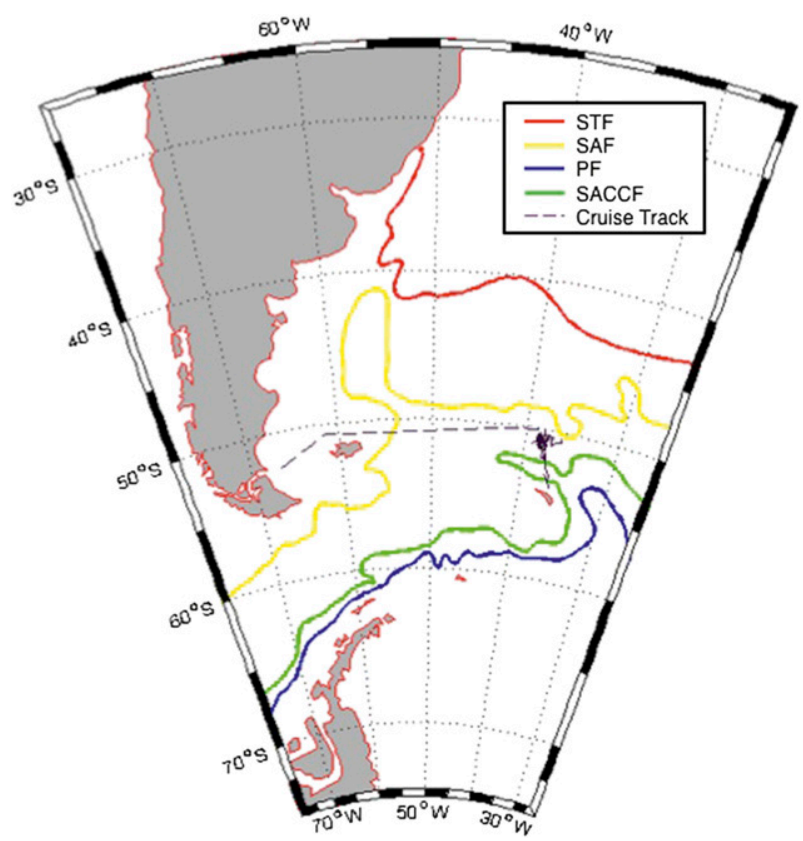

FIG. 7. The location of the SOGasEx, including the cruise track (black dashed line). The island that appears to the south of the cruise track is southern Georgia. The ocean fronts, including the subtropical front (STF; red line), the subantarctic front (SAF; yellow line), the polar front (PF; blue line), the southern Antarctic Circumpolar Current front (SACCF; green line) are included for reference.

\section{4) TSK SWHM: SHIPBORNE WAVE HEIGHT METER}

The TSK, a nadir-looking continuous microwave Doppler radar, was used to measure wave height within the range of 0 to $14.5 \mathrm{~m}$ with a resolution of $14.5 \mathrm{~cm}$ at a sampling frequency of $10 \mathrm{~Hz}$. At an approximate height of $8 \mathrm{~m}$ above the sea level, the TSK (with a half angle antenna radiation beam of $6.5^{\circ}$ ) produced a footprint $1.8 \mathrm{~m}$ in diameter, corresponding to a wavenumber ( $k$ of $1.74 \mathrm{rad} \mathrm{m}^{-1}$ ) and a maximum resolution of approximately $0.7 \mathrm{~Hz}$. The radial component of the velocity relative to the observer (i.e., the instrument) was integrated to yield displacement. Final sea surface displacement measurements were obtained from the TSK shipborne wave height meter (SWHM) signal by correcting for the heave of the ship at the bow [Eq. (2)].

\section{Instrument intercomparison}

A comprehensive comparison of the measured 1D frequency spectra collected using the WaMoS, Riegl, and TSK was completed to test instrument performance (Fig. 4). Instruments were evaluated based on (i) total spectral energy (spectral variance $\mathrm{m}^{2}$ ), from which the significant height was approximated $\left(H_{s} \mathrm{~m}\right)$; (ii) spectral 

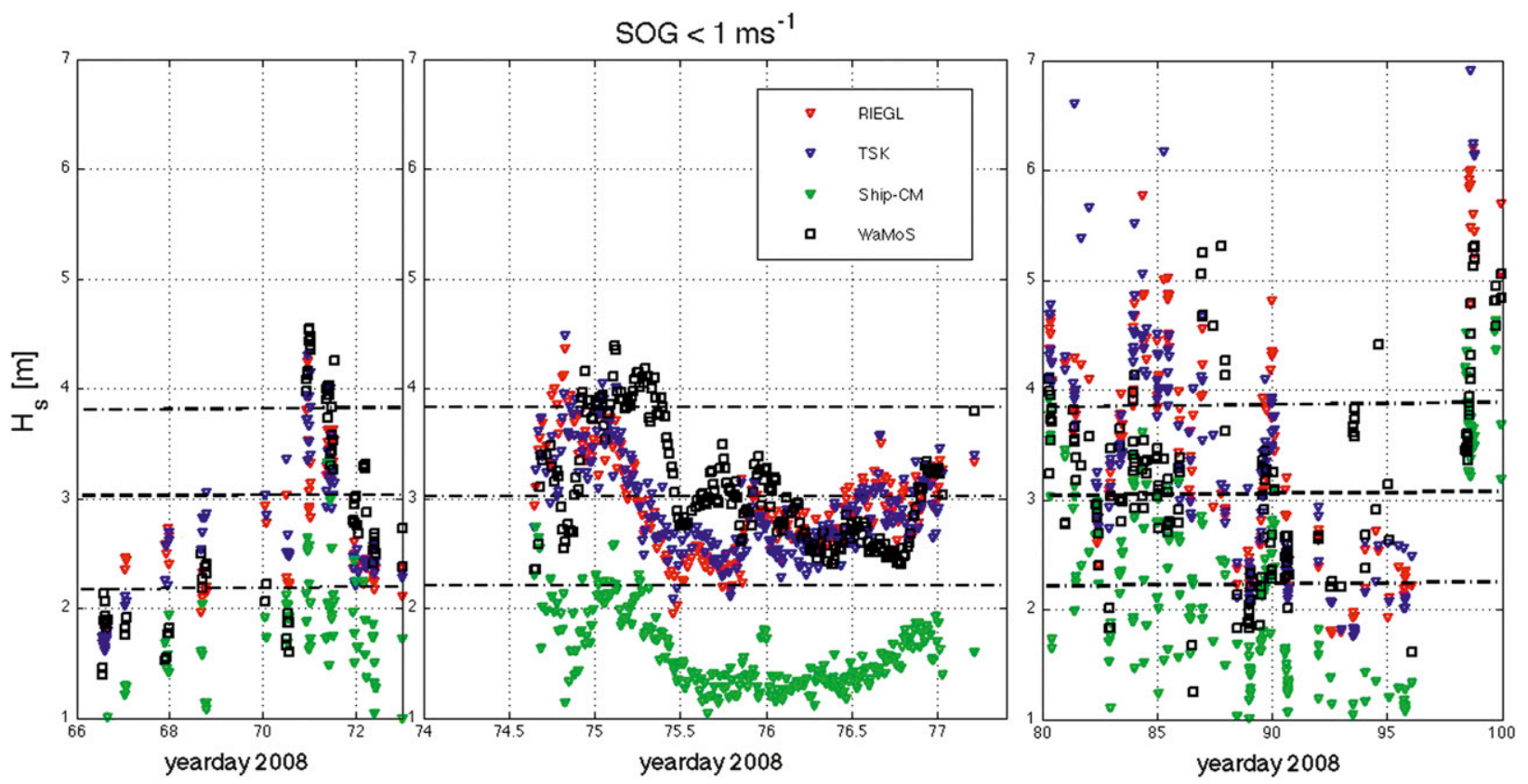

FIG. 8. The time series of significant wave height estimates $\left(H_{s}\right)$ collected by the Riegl (red triangles), TSK (blue triangles), ship-CM (green triangles, with no $\alpha_{m}$ weighting factor), and WaMoS (black squares) during slow underway speeds ( $\mathrm{mean} \mathrm{SOG}=0.25 \mathrm{~m} \mathrm{~s}^{-1}$ ). The data shown correspond to an average. The WaMoS resolved a mean $H_{s}$ of $3.01 \mathrm{~m}$ (black dashed line, one standard deviation black dotted lines).

peak information $\left(T_{p}=1 / f_{p}\right)$, where $f_{p}$ is the peak frequency (the remaining spectral variables were obtained using the deep water dispersion relation); and (iii) spectral shape and tail behavior at high frequencies $(f>1 \mathrm{~Hz})$ in an effort to resolve the widest frequency range possible. Based on the average peak characteristics recorded by WaMoS, the state of the wave field is characterized using the inverse wave age defined as the wind speed to peak phase speed ratio: $U_{10} / c_{p}$ (Fig. 5). This ratio was used to further define the overall existing conditions during the field campaign. The significant wave height for all instrumentation was estimated from the spectral density function following

$$
H_{s}=4 \sqrt{\left(\sigma^{2}\right)}
$$

where $\sigma^{2}$ is the variance of the sea surface displacement signal $\eta(t)$ given by the integral of the frequency spectrum

$$
\sigma^{2}=\int S(f) d f
$$

where $S(f)$ is calculated by taking the FFT of the sea surface displacement time series provided by the Riegl, TSK, and ship-CM. For the WaMoS system, the frequency spectra follow directly from

$$
S(f)=\int \Psi(f, \theta) d \theta
$$

where $\Psi(f, \theta)$ is the directional frequency spectrum, and integration is carried over $\theta=[0: 2 \pi]$, accounting for waves in all directions.

For the deep water gravity waves here analyzed, the frequency and wavenumber are related via the dispersion relation

$$
\omega^{2}=g k
$$

where $\omega$ is the radian frequency $(\omega=2 \pi f), k$ is the wavenumber, and $g$ is the gravitational acceleration. The phase speed of the waves is then given by $c=\sqrt{g / k}$. The peak frequency $f_{p}$ was used to calculate the peak wavenumber $k_{p}$ and phase speed $c_{p}$. The peak phase speed corresponds to the speed of the dominant wave, which, for open-ocean conditions, is the swell component of the wave field. From the spectral peak, the wave age, or state of the wave field, was defined, where a wave field is considered young or developing if the inverse wave age, $U_{10} / c_{p} \geq 0.82$, is mature or fully developed when $U_{10} / c_{p} \sim 0.8$ and old or decaying when $U_{10} / c_{p}<0.8$ (Fig. 5).

The direction of the instrumentation relative to the wind and waves is a key component of successful sampling 
(Fig. 6). Atmospheric and flux measurements, particularly wind speed and friction velocity, are best resolved when flow distortion is avoided; therefore, ideal measurements follow when the ship was positioned heading into the wind. Similarly, the Riegl and TSK produce high fidelity measurements during times when the waves propagate toward the ship, avoiding blockage from the ship's bow and wake. Therefore, the observations presented here satisfy the following conditions:

$$
\begin{aligned}
0.8 \leq \theta_{\text {wind }} / \theta_{\text {wave }} & \leq 1.2 \text { and } \\
0.8 & \leq \theta_{\text {wind }} / \Theta_{\text {heading }} \leq 1.2,
\end{aligned}
$$

where $\theta_{i}$ corresponds to the direction of wind and waves in meteorological convention (i.e., direction from) and $\Theta_{\text {heading }}$ is the ship's heading. For example, $\theta_{\text {wind }} / \Theta_{\text {heading }}=1$ when the winds are from the west and the ship is heading west. This minimizes blockage of the wave field by the ship for the instrumentation mounted on the bow.

\section{a. Doppler shifting}

The largest Doppler shift occurs when the ship is cruising into waves that are propagating toward the bow. The difference between the intrinsic frequency $(\widetilde{f})$ and the observed frequency $f_{\text {obs }}$ for the in-line scenario was determined following Hanson et al. (1997). The Doppler shift, which is a function of the ship's speed relative to the surface current, was obtained using measurements from the GPS and WaMoS respectively. The Dopplershifted frequency was determined following

$$
\tilde{f}=\frac{g}{4 \pi U_{r}}\left[\sqrt{1+\left(\frac{8 \pi U_{r} f_{\text {obs }}}{g}\right)}-1\right],
$$

where $U_{r}$ is the speed of the ship relative to the mean current and $g$ is the gravitational acceleration. A scaling factor $(\widetilde{\delta f})$ was applied to the corrected spectra in order to ensure the conservation of energy under the curve. The following relationship was used:

$$
S(f)=\widetilde{S}(f) \frac{\widetilde{\delta f}}{\delta f}
$$

where $S(f)$ is the corrected spectral density. The term $\widetilde{\delta f}$ corresponds to the intrinsic frequency resolution that is a function of $U_{s}$. The Doppler shift introduced by the relative motion of the ship and waves has an important effect on the maximum frequency resolution for the Riegl and TSK. Doppler correction and the shift in the maximum spectral resolution is addressed in the underway section for SOG $>1 \mathrm{~m} \mathrm{~s}^{-1}$.
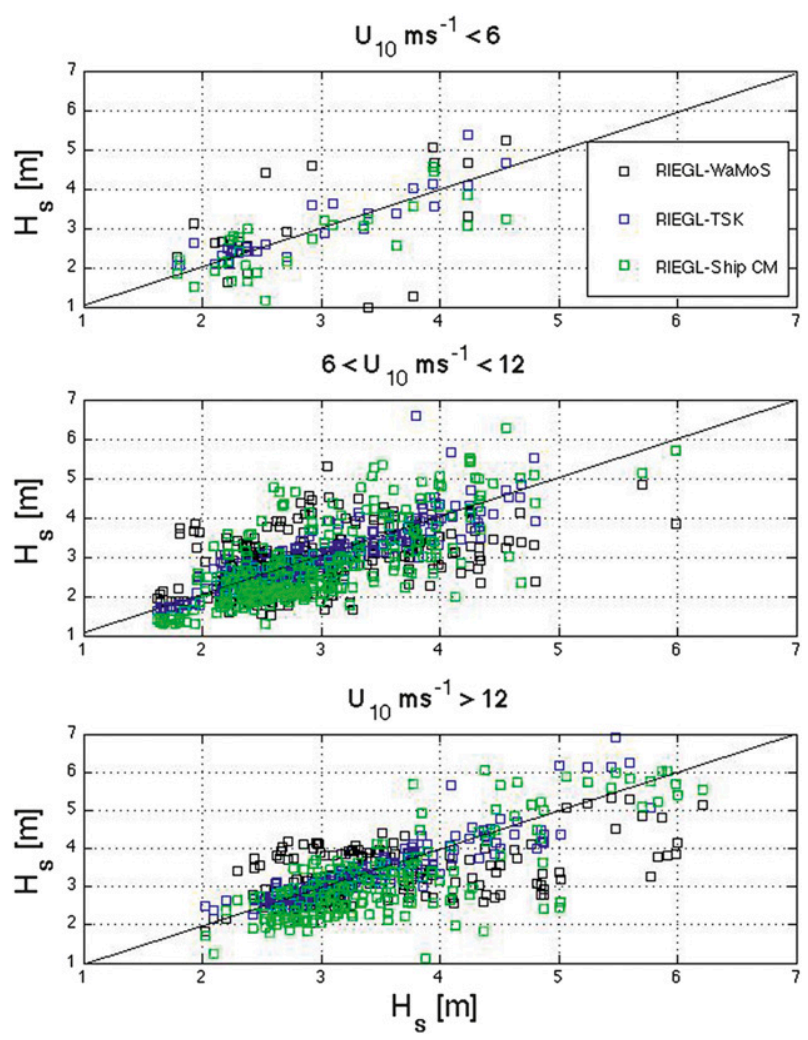

FIG. 9. The 1:1 significant wave height $\left(H_{s}\right)$ comparison under different wind forcing while station keeping. The $H_{s}$ estimates from the WaMoS (black squares), TSK (blue squares), and Ship-CM (green squares, with $\alpha_{m}$ weighting factor) were plotted against Riegl data for three wind conditions including (top) $U_{10}<6 \mathrm{~m} \mathrm{~s}^{-1}$, (middle) $6<U_{10}<12^{-1}$, and (bottom) $U_{10}>12^{-1}$.

\section{b. Motion contamination}

Thus far, only the vertical displacement of the bow relative to the sea surface has been considered. Any added motion contamination due to instrument tilt has been ignored. Tilt could be a contributing factor, however; therefore, we consider the potential of a "ghost" wave field produced by instrument tilt. Assuming the lead order perturbation is produced by pitch (i.e., no heave), then the response of the ship would be linear, with only instrument oscillation (i.e., pitch and roll) adding energy to the signal from point-based measurements. For example, the distance to the unperturbed mean surface is $B_{o}$ (meters) for the Riegl at a height of $10 \mathrm{~m}\left(H_{i}=10 \mathrm{~m}\right)$ and an incidence angle of $\alpha$ is given by

$$
B_{o}=H_{i} / \cos (\alpha),
$$

from which the horizontal distance $d=B_{o} \sin \left(a_{1}\right) \mathrm{m}$ is defined. For $\theta>0$ (i.e., positive pitch), the perturbed distance due to the pitch $\left(B_{p}\right)$ to the mean surface is 

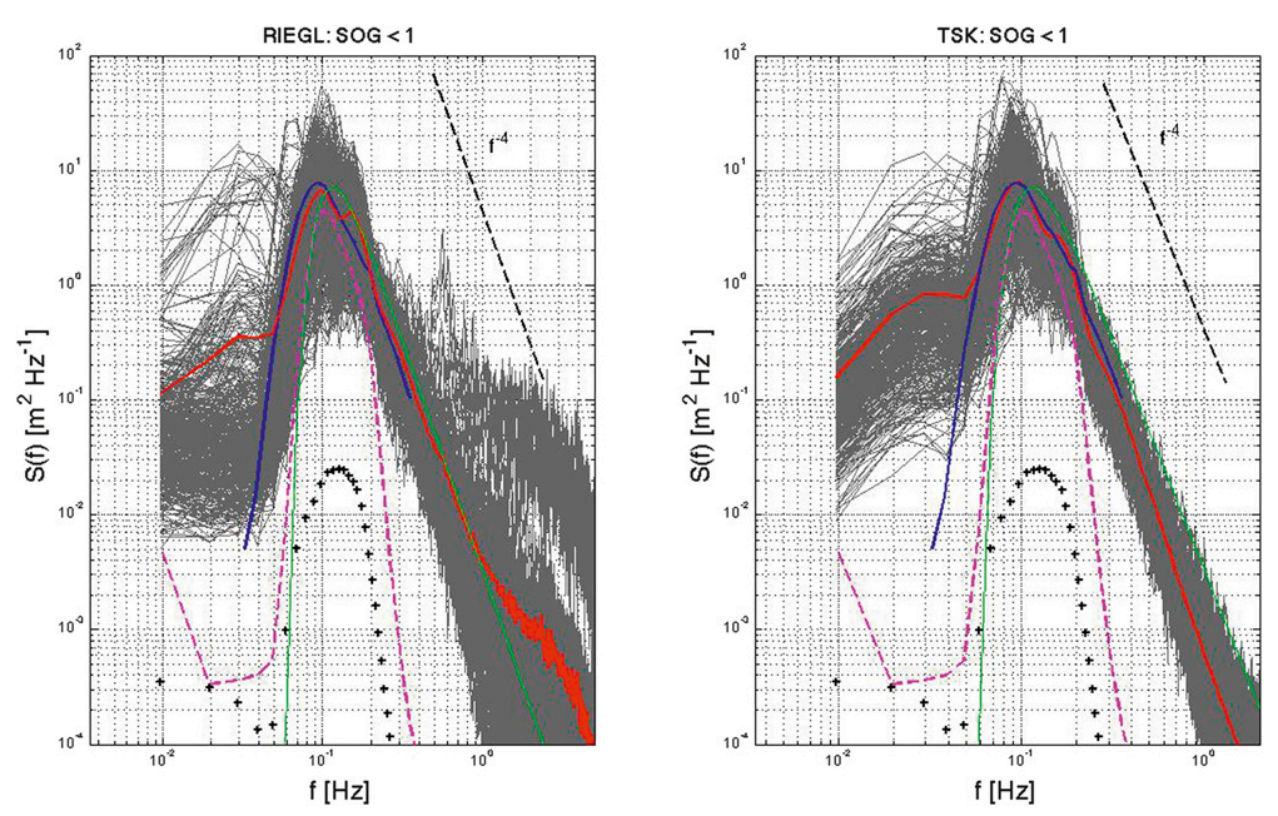

FIG. 10. Station-keeping 1D average wave spectra measured using the Riegl (red line) and the TSK (red line) compared to the WaMoS (blue line) and ship-CM (dashed magenta line) wave spectra. The Donelan et al. (1985) spectral parameterization (mean $U_{10}=11.13 \mathrm{~m} \mathrm{~s}^{-1}$; green line) and a frequency slope of $f^{-4} \mathrm{~Hz}$ (black dashed line) are included for reference. (left) Riegl-measured spectral realizations $(n=$ 504,30 -min averages) for SOG $<1 \mathrm{~m} \mathrm{~s}^{-1}$ (gray lines). (right) TSK-measured spectral realizations $(n=$ 504,30 -min averages) for SOG $<1 \mathrm{~m} \mathrm{~s}^{-1}$ (gray lines).

$$
\begin{gathered}
B_{p}(t)=\left[d \sin \left(a_{1}\right) / \sin \left(a_{2}\right)\right] \sin [\theta(t)] / \sin \left(a_{1}\right) \quad \text { and } \\
B_{f}(t)=B_{p} / \cos [\psi(t)],
\end{gathered}
$$

where $a_{1}=90-\alpha^{o}, a_{2}=90-\theta(t)+\alpha$, and $B_{f}$ is the final perturbation if the roll effects are added. For $\theta<0$ (i.e., negative pitch), the perturbed distance $B_{p}$ is given by

$$
\begin{aligned}
& B_{p}(t)=d\left\{\sin [\theta(t)] / \sin \left(a_{3}\right)\right\} \quad \text { and } \\
& B_{f}(t)=B_{p} / \cos [\psi(t)],
\end{aligned}
$$

where $a_{3}=-[90-\theta(t)+\alpha]$. This assumes a "two-step tilting": first a pitch and then a roll that will always enhance the perceived distance between the instrument and the mean sea surface. This estimation heavily weights the pitching of the instrument. Potential nonlinear effects and the convolution of the pitching and rolling are not explored. The final distance perturbation $\left[B_{f}(t) ; \mathrm{m}\right]$ is used to generate the spectra of what is defined a ghost wave field, only to be present because of instrument angular rotation.

\section{Results}

The SOGasEx was conducted during moderate to high winds $\left(5 \leq U_{10} \leq 18 \mathrm{~m} \mathrm{~s}^{-1}\right)$ with a severe wind event
$\left(U_{10}>18 \mathrm{~m} \mathrm{~s}^{-1}\right)$ at the culmination of the field campaign (yeardays 96-99; Figs. 3, 5). Mature wave field conditions, with a weakly bimodal spectral distribution due to the wind wave peak often buried under the swell component of the wave field, were observed throughout the experiment. The observed wind wave conditions are consistent with the general circulation patterns of the region. On average, a dominant westerly wind prevails between the subtropical high pressure system and the subpolar low pressure system $\left(\left\langle\theta_{\text {wind }}\right\rangle=278^{\circ} \pm 67^{\circ}\right)$. The westerly wind exerts a total stress ranging between 0.12 and $0.2 \mathrm{~N} / \mathrm{m}^{2}$, driving the Antarctic Circumpolar Current through the Drake Passage (Fig. 7) and connecting the Pacific and the Atlantic Oceans. With no fetch limitations, the waves, winds, and currents wrap around this landless stretch of ocean, with ample space and time to evolve and develop. As a result, a relatively constant wave direction develops $\left(\left\langle\theta_{\text {wave }}\right\rangle=256^{\circ} \pm 46^{\circ}\right)$. The dominant waves (composed of the background, swell component of the wave field) fall within a frequency range of $0.08 \leq f \leq 0.12 \mathrm{~Hz}$. A total wave field developed in line with the winds, resulting in wind waves riding on top of the swell component. Most of the variability in the wind versus wave direction was due to oscillations in wind direction, where the wave field does not have sufficient time to adapt to the fleeting directional fluctuations 

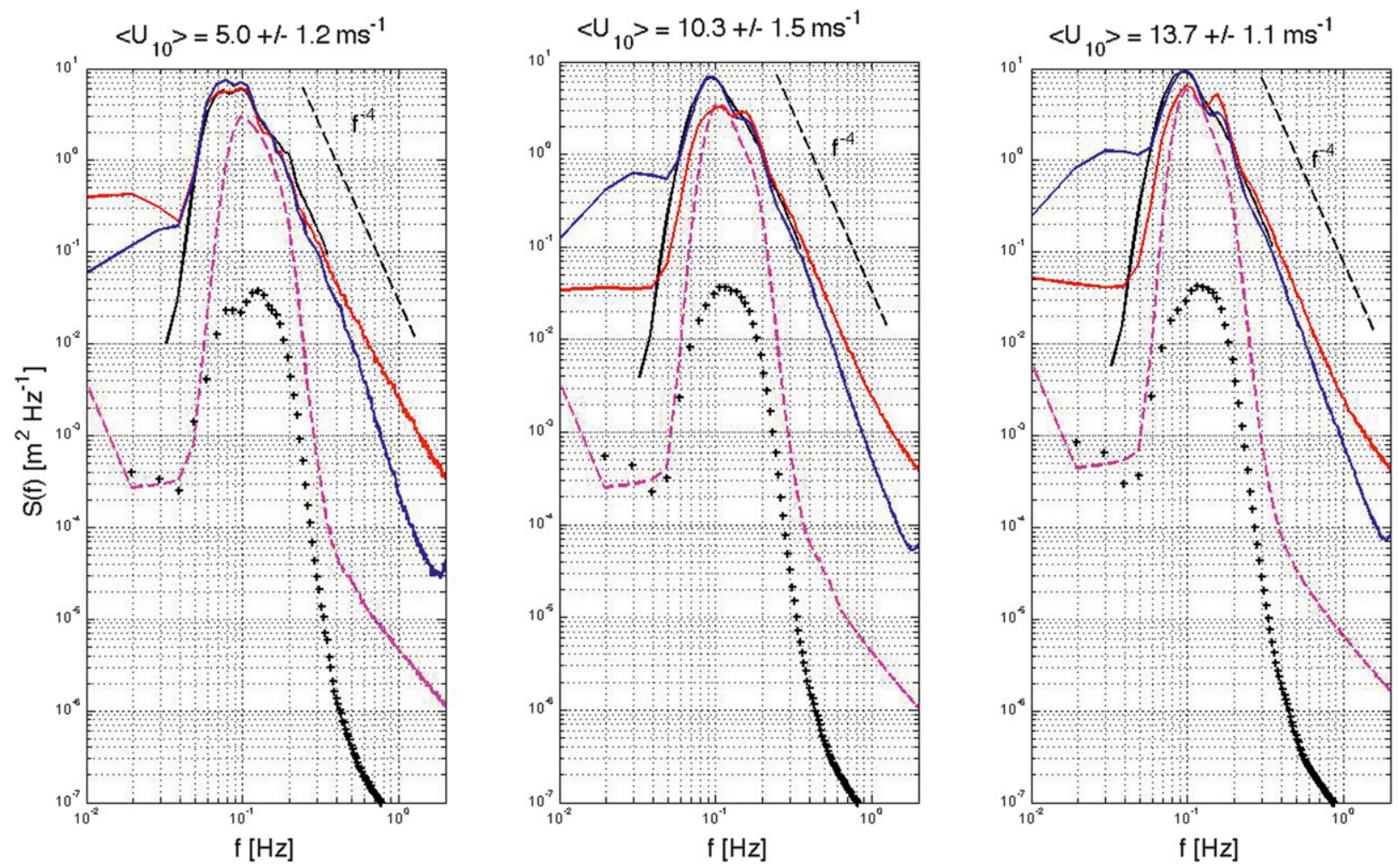

FIG. 11. Station-keeping average wave spectra for the Riegl (red line), TSK (blue line), WaMoS (black line), and ship-CM (magenta dashed line) for different wind conditions. (left) Average $\left(n=29,30\right.$-min average) wave spectra collected during low wind, $U_{10}=5.0 \mathrm{~m} \mathrm{~s}{ }^{-1}$, conditions. (middle) Average ( $n=267,30$-min average) wave spectra collected during moderate wind, $U_{10}=10.3 \mathrm{~m} \mathrm{~s}^{-1}$, conditions. (right) Average ( $n=208,30$-min average) wave spectra collected during high wind, $U_{10}=13.7 \mathrm{~m} \mathrm{~s}^{-1}$, conditions high wind shows 208 spectral realizations of $30 \mathrm{~min}$ each. The frequency slope of $f^{-4} \mathrm{~Hz}$ (black dashed line) and the ghost wave field from added pitch (black pluses) are included for reference.

in the wind forcing. Ultimately, approximately $54 \%$ of the SOGasEx observations lie within the range of $-40^{\circ}<\theta_{\text {wind }}-\theta_{\text {wave }}<40^{\circ}$.

Instrument comparisons are divided into two categories defined using the ship's SOG: station-keeping (section 4a) and underway (section 4b) measurements. The station-keeping measurements, collected when SOG $\leq 1 \mathrm{~m} \mathrm{~s}^{-1}, \theta_{\text {wind }} / \Theta_{\text {heading }}=1$, and the Doppler shift is minimized, represent ideal sampling conditions. Therefore, the station-keeping results provide the basis for the analysis of underway measurements.

\section{a. Station keeping}

One-third of the SOGasEx data was collected under station-keeping conditions. Half of the station-keeping measurements were collected during yeardays 74-77 $\left(\langle\mathrm{SOG}\rangle=0.25 \mathrm{~m} \mathrm{~s}^{-1}\right)$ at a location northeast of South Georgia Island. The mean wind speed during station keeping was $\left\langle U_{10}\right\rangle=11.2 \pm 2.7 \mathrm{~m} \mathrm{~s}^{-1}$ with overall old to decaying seas, where $\left\langle U_{10} / c_{p}\right\rangle=0.72 \pm 0.2$ (Fig. 5). The mean surface current while on station, measured using the WaMoS system, was $\left\langle U_{s}\right\rangle=0.28 \mathrm{~m} \mathrm{~s}^{-1}$.
Doppler shift and aliasing were determined from the speed of the ship relative to the currents $\left(U_{r}=\right.$ SOG $U_{s} \mathrm{~m} \mathrm{~s}^{-1}$ ). The average relative direction between the ship's heading and the surface current direction was $\gamma=53^{\circ}$. The difference between the maximum resolution frequencies (i.e., observed frequencies $f_{\text {obs }}$ ) and the intrinsic frequencies (Doppler shift accounted $f_{\text {int }}$ ) was calculated following Eq. (8). Given the relative motion of the ship and currents, the Riegl resolved wave scales as low as $4.6 \mathrm{~Hz}$, which represents a $10 \%$ loss in resolution. The TSK, which has a maximum resolution of $0.7 \mathrm{~Hz}$, experienced a $2 \%$ reduction in resolution (i.e., $\sim 0.68 \mathrm{~Hz}$ ). At the spectral peak (approximately

TABLE 1. Peak frequency $\left(f_{p} ; \mathrm{Hz}\right)$ for SOG $\leq 1 \mathrm{~m} \mathrm{~s}^{-1}$ under different wind regimes. The mean $f_{p}$ is reported $\pm 1 \sigma$.

\begin{tabular}{lrrr}
\hline \hline \multicolumn{1}{c}{$f_{P}$} & $U_{10}=5.0 \mathrm{~m} \mathrm{~s}^{-1}$ & $U_{10}=11.0 \mathrm{~m} \mathrm{~s}^{-1}$ & \multicolumn{1}{c}{$U_{10}=13.7 \mathrm{~m} \mathrm{~s}^{-1}$} \\
\hline WaMoS & $0.090 \pm 0.014$ & $0.10 \pm 0.016$ & $0.090 \pm 0.013$ \\
Riegl & $0.090 \pm 0.017$ & $0.12 \pm 0.046$ & $0.11 \pm 0.043$ \\
TSK & $0.090 \pm 0.019$ & $0.11 \pm 0.026$ & $0.090 \pm 0.039$ \\
Ship-CM & $0.10 \pm 0.016$ & $0.11 \pm 0.012$ & $0.11 \pm 0.012$ \\
\hline
\end{tabular}




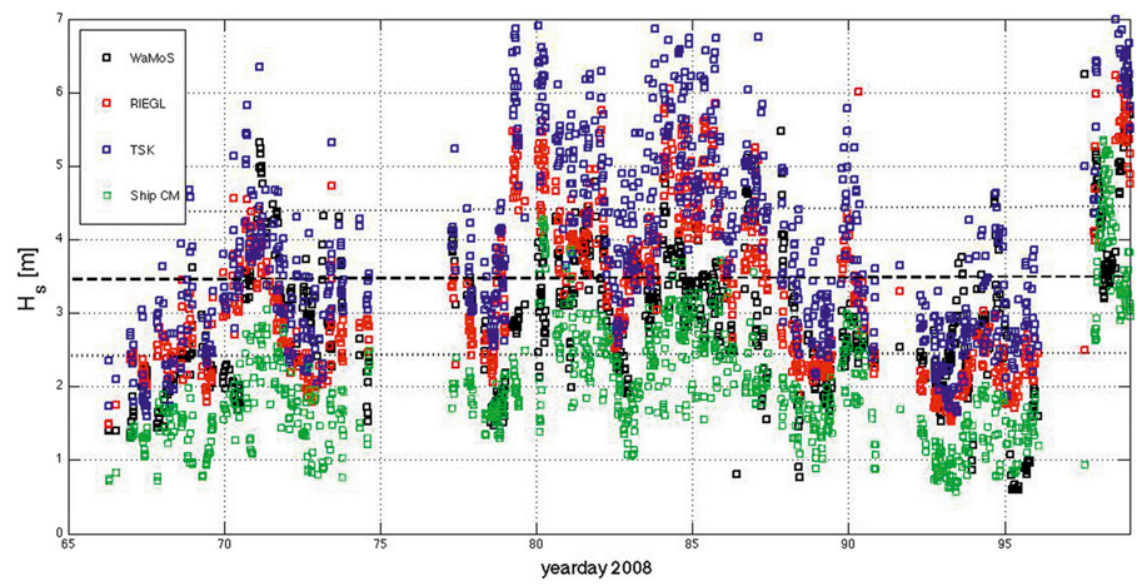

FIG. 12. Time series estimates of significant wave height collected by the WaMoS (black circles), Riegl (red circles), TSK (blue circles), and the ship-CM (green triangles, with no $\alpha_{m}$ weighting factor) collected during SOG $>1 \mathrm{~m} \mathrm{~s}^{-1}$. The mean significant wave height $\left(H_{s}=\right.$ 3.52 ) is included for reference (black dashed line).

$0.1 \mathrm{~Hz}$ ) the difference was less than $1 \%$; therefore, no Doppler correction was made and aliasing issues were disregarded.

Ship-CM, Riegl, TSK, and WaMoS retrieved time series measurements of significant wave height $\left(H_{s}\right)$ [following Eqs. (2) and (3)] were compared for consistency (Fig. 8). For the full range of measured $H_{s}$ values, no statistically significant difference was found between the Riegl and TSK ( $p=0.05$; Fig. 9). The mean value of $H_{s}$ retrieved using the WaMoS was statistically significantly different $(p=0.05)$ compared to $H_{s}$ values from the Riegl. The WaMoS system consistently provided $H_{s}$ values $3 \%-5 \%$ lower than those obtained from the Riegl and TSK for $1.5<H_{s}<4 \mathrm{~m}$. During rougher seas $\left(H_{s}>4 \mathrm{~m} ; U_{10}>12.0 \mathrm{~m} \mathrm{~s}^{-1}\right)$, however, the WaMoS system underestimated the wave height by $20 \%-25 \%$ compared to the Riegl and TSK (Fig. 9).

The total variance of the ship-CM spectra, and therefore direct estimates of $H_{s}$ by the ship-CM, was consistently lower than the Riegl and TSK by a factor of

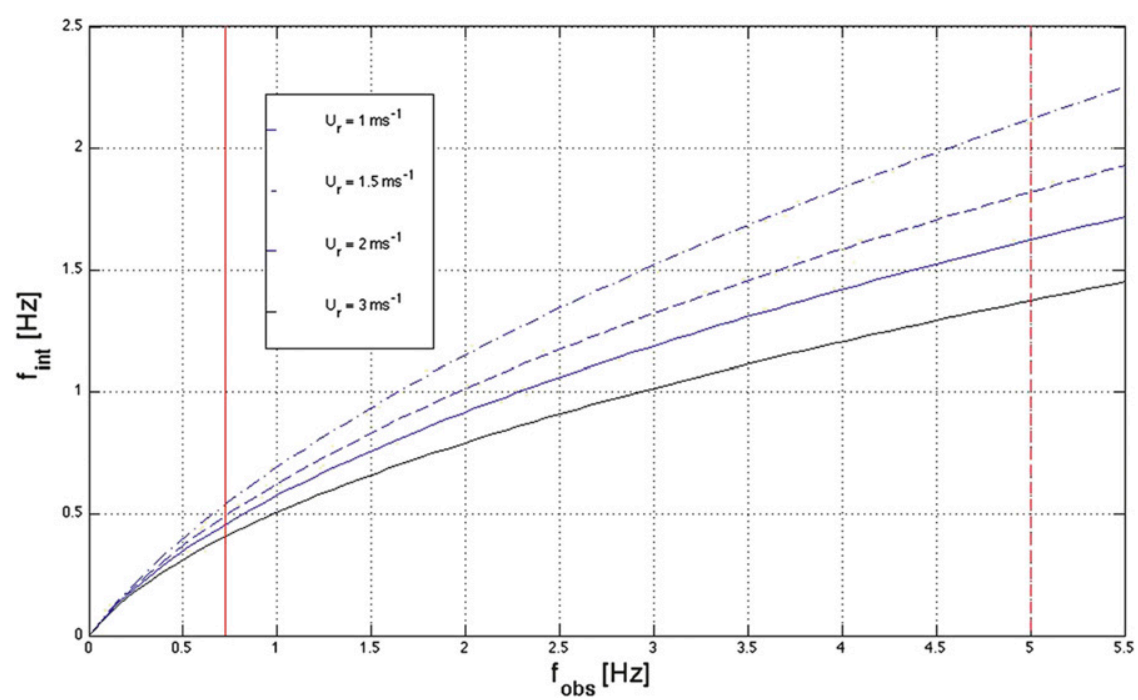

FIG. 13. The intrinsic frequency $\left(f_{\text {int }}\right)$ as a function of the observed frequency $\left(f_{\text {obs }}\right)$ for different relative speeds, including $U_{r}=1 \mathrm{~m} \mathrm{~s}^{-1}$ (blue dotted-dashed line), $U_{r}=1.5 \mathrm{~m} \mathrm{~s}^{-1}$ (blue dashed line), $U_{r}=2 \mathrm{~m} \mathrm{~s}^{-1}$ (blue solid line), and $U_{r}=3 \mathrm{~m} \mathrm{~s}^{-1}$ (black solid line). For increasing $U_{r} \mathrm{~m} \mathrm{~s}^{-1}$, the maximum instrument resolution decreases. The maximum resolution of the TSK for an ideal scenario (i.e., based on specifications of the instrument) is $0.7 \mathrm{~Hz}$ (red line). The maximum resolution of the Riegl is $5 \mathrm{~Hz}$ (red dashed line). 

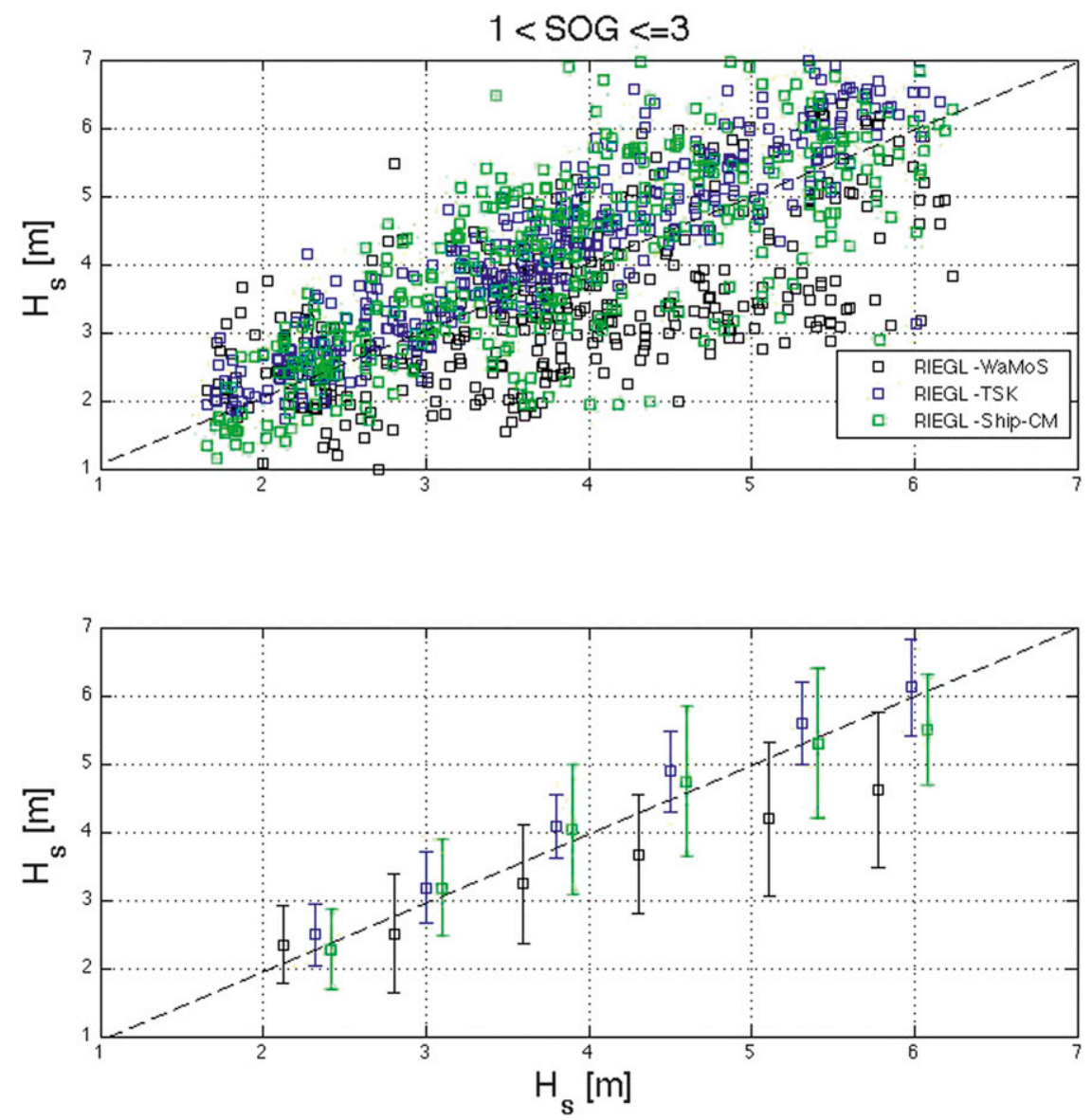

FIG. 14. (top) The 1:1 significant wave height $\left(H_{s}\right)$ comparison collected while underway at slow speeds. The $H_{s}$ estimates from the WaMoS (black squares), TSK (blue squares), and ship-CM ( $\alpha_{m}$ weighted, green squares) were plotted against Riegl data. (bottom) Bin-averaged $H_{s}$ data from the top. The Riegl-ship-CM comparison are displaced $0.3 \mathrm{~m}$ in the $x$ axis and the Riegl-TSK are displaced $0.2 \mathrm{~m}$ in the $x$ axis to aid in visualization.

$1.63\left(\alpha_{m}=1.63 \pm 0.25\right)$. The underestimation of $H_{s}$ by the ship-CM was the result of the ship acting as a low pass, producing strong rolloff for frequencies larger than $0.2 \mathrm{~Hz}$ (Fig. 10). The ship-CM captured the energy in the frequency range $0.05<f<0.2 \mathrm{~Hz}$, where $\alpha_{m}$ was retrieved from the variance of the ETFE between the ship-CM spectral response (output) and the Riegl and TSK spectral responses (input). The max amplitude of the ETFE while on station was 1.35 at $\sim 0.12 \mathrm{~Hz}$. Ultimately, the mean significant wave heights produced by all instrumentation (including the $\alpha_{m}$-weighted ship-CM data) were within $10 \%-13 \%$ for $1.5<H_{s}<4 \mathrm{~m}$.

Among all instrumentation, spectral magnitude and shape were in agreement within $10 \%-12 \%$ for the entire range of wind forcing analyzed (Figs. 10, 11). The strongest agreement was found between the Riegl and TSK; however, the noise level of the Riegl (approximately $-20 /-15 \mathrm{~dB}$ ) exceeded that of the TSK (approximately $-30 \mathrm{~dB}$ ), particularly at $f>1.3 \mathrm{~Hz}$. This white noise was likely due to the high-frequency vibrations of the ship's jackstaff. The flattening of the spectral slope rolloff at $f>1.3 \mathrm{~Hz}$ in the Riegl data was explained by adding white noise to the signal. The TSK showed a deviation from the $f^{-4}$ toward a faster rolloff, $\sim f^{-5}$, at $f_{i} \sim 0.4-0.5 \mathrm{~Hz}$. Therefore, the TSK rolloff occurred at a lower frequency than the theoretical maximum frequency

TABLE 2. Peak frequency $\left(f_{p} ; \mathrm{Hz}\right)$ while underway for different SOG. The mean $f_{p}$ is reported $\pm 1 \sigma$.

\begin{tabular}{lccc}
\hline \hline \multicolumn{1}{c}{$f_{P}$} & $\begin{array}{c}1<\mathrm{SOG} \leq \\
3 \mathrm{~m} \mathrm{~s}^{-1}\end{array}$ & $\begin{array}{c}3<\mathrm{SOG} \leq \\
6 \mathrm{~m} \mathrm{~s}^{-1}\end{array}$ & SOG $>6 \mathrm{~m} \mathrm{~s}^{-1}$ \\
\hline WaMoS & $0.090 \pm 0.014$ & $0.096 \pm 0.016$ & $0.080 \pm 0.012$ \\
Riegl & $0.090 \pm 0.049$ & $0.074 \pm 0.040$ & $0.060 \pm 0.035$ \\
TSK & $0.090 \pm 0.040$ & $0.070 \pm 0.020$ & $0.060 \pm 0.040$ \\
Ship-CM & $0.10 \pm 0.018$ & $0.090 \pm 0.026$ & $0.090 \pm 0.020$ \\
\hline
\end{tabular}



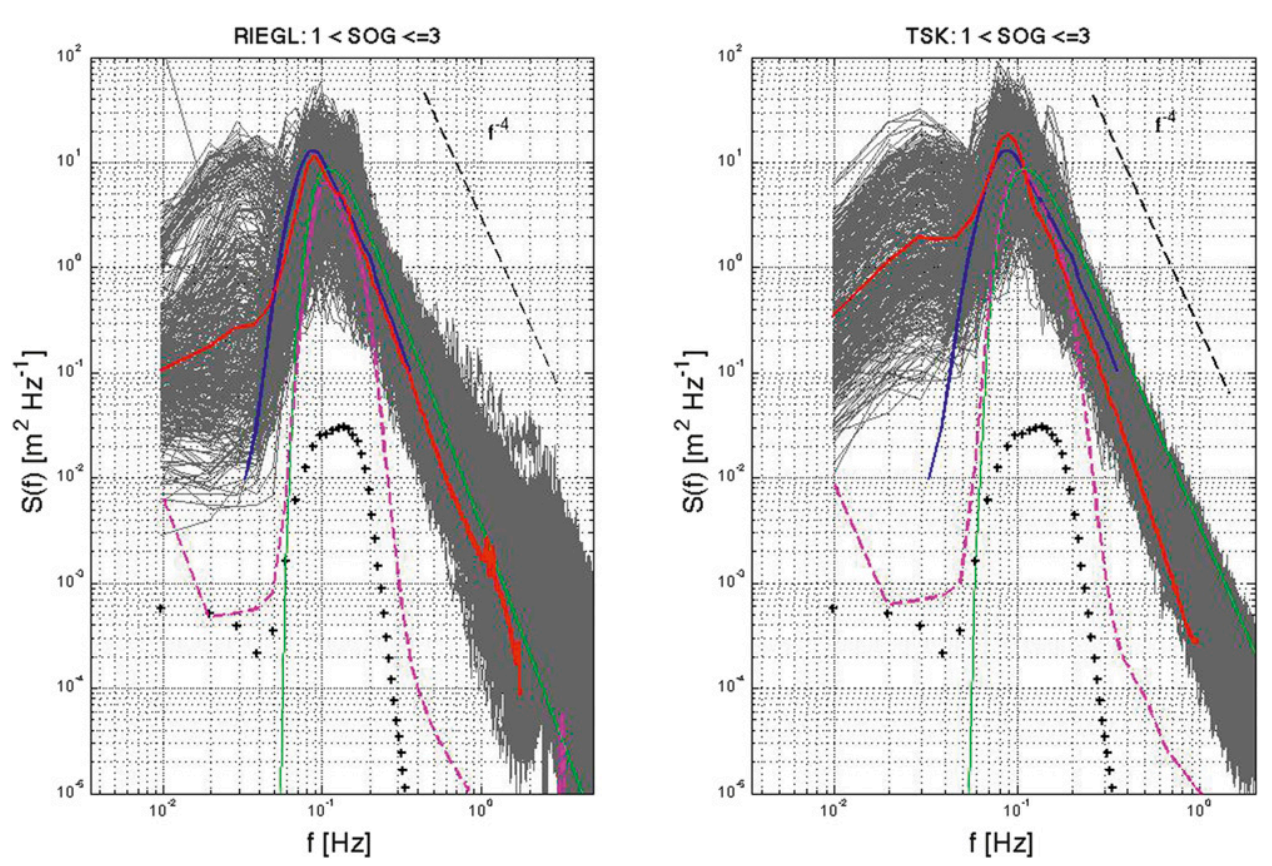

FIG. 15. Average wave frequency spectra measured using the Riegl (red line; $n=456,30$-min averages) and TSK (red line; $n=456,30$-min averages) compared to the WaMoS (blue line) and ship-CM (dashed magenta line) wave spectra collected while underway at slow speeds $\left(1<\mathrm{SOG} \leq 3 \mathrm{~m} \mathrm{~s}^{-1}\right)$. The Donelan et al. (1985) spectral parameterization (mean $U_{10}=11.6 \mathrm{~m} \mathrm{~s}^{-1}$; green line) and a frequency slope of $f^{-4} \mathrm{~Hz}$ (black dashed line) are included for reference. (left) Riegl-measured spectral realizations $(n=$ 456, 30-min averages) for $1<\mathrm{SOG} \leq 3 \mathrm{~m} \mathrm{~s}^{-1}$ (gray lines). (right) TSK-measured spectral realizations ( $n=456,30$-min averages) for $1<\mathrm{SOG} \leq 3 \mathrm{~m} \mathrm{~s}^{-1}$ (gray lines).

resolution of $0.7 \mathrm{~Hz}$ (estimated from the instrument footprint). The spectral peak is well characterized for all instrumentation (see Table 1).

The secondary peak observed in the Riegl measurements collected during station keeping was likely a wind wave peak, which is consistent with spectra analyzed under increased wind forcing (Fig. 11). With increasing wind forcing, the amplitude of the ETFE showed no coincident increase and a peak frequency that strongly correlated with the swell at $\sim 0.1 \mathrm{~Hz}$. Therefore, the ship's leading response did not add energy at the assumed wind frequency of $\sim 0.2 \mathrm{~Hz}$. The magnitude of the ghost wave field was also low and no added tilt-induced contamination could be used to explain the observed peak. Consequently, the Riegl was adequately corrected for motion contamination and was capable of capturing the highfrequency portion of the wave field while on station.

Finally, during station keeping there is a good agreement in $H_{s}$ estimates and data collected using the WaMoS and Riegl systems were easily merged to produce a full 1D spectrum from 0.035 to $1.5 \mathrm{~Hz}$. Complementing datasets collected using the TSK and WaMoS produced spectra ranging from 0.035 to $0.5 \mathrm{~Hz}$. The TSK data exhibited less variance but lacked the high-frequency range provided by the Riegl. Finally, the ship-CM system proved useful for estimating spectral shape at low frequencies after accounting for the magnitude of the transfer function, approximated by the ETFE peak amplitude and variance.

\section{b. Underway measurements $\left(S O G \geq 1 \mathrm{~ms}^{-1}\right.$ )}

The same metrics used during station keeping ( $\mathrm{SOG}<$ $1 \mathrm{~m} \mathrm{~s}^{-1}$ ) were applied in the instrument comparison conducted on underway measurements ( $\mathrm{SOG}>1 \mathrm{~m} \mathrm{~s}^{-1}$ ). Comparisons were performed for two underway categories: $1<\mathrm{SOG} \leq 3 \mathrm{~m} \mathrm{~s}^{-1}$ and $3<\mathrm{SOG} \leq 6 \mathrm{~m} \mathrm{~s}^{-1}$. The same directional constraints applied to station-keeping data were used on underway data.

$$
\text { 1) UNDERWAY: } 1<S O G \leq 3 M S^{-1}
$$

Old to decaying seas, $\left\langle U_{10} / c_{p}\right\rangle=0.69 \pm 0.22$, were observed while underway at slow speeds (mean $\langle\mathrm{SOG}\rangle=$ $2.2 \mathrm{~m} \mathrm{~s}^{-1}$ ). During the SOGasEx field campaign, $70 \%$ of the data collected satisfied the underway condition (SOG $\geq 1 \mathrm{~m} \mathrm{~s}^{-1}$ ) with $40 \%$ of them falling in the $1<$ SOG $\leq 3 \mathrm{~m} \mathrm{~s}^{-1}$ bin. Significant wave height measurements collected using the Riegl and TSK while underway at slow speeds ranged from 1.6 to $6.9 \mathrm{~m}$ (Fig. 12). The 

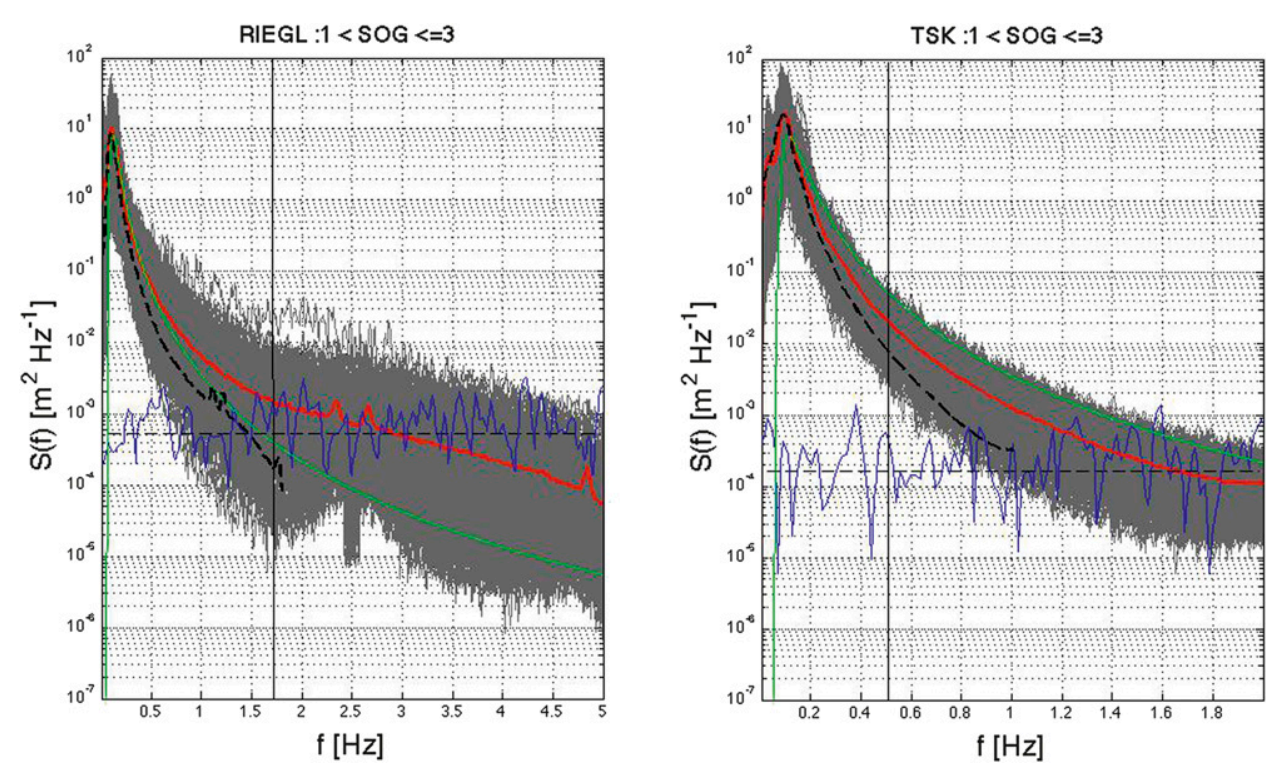

FIG. 16. Average spectral tail measurements collected while underway at slow speeds $(1<\mathrm{SOG} \leq$ $3 \mathrm{~m} \mathrm{~s}^{-1}$ ) using the Riegl (red line) and the TSK (red line) were compared to the Donelan et al. (1985) spectral parameterization (mean $U_{10}=11.6 \mathrm{~m} \mathrm{~s}^{-1}$; green line). The reduction in each instrument's maximum frequency resolution, defined as the high-frequency cutoff, is included (black solid line). Average spectral tail measurements after Doppler correction and accounting for aliasing are included for both instruments (black dashed line). (left) Riegl-measured wave spectra ( $n=456,30$-min averages) for $1<\mathrm{SOG} \leq 3 \mathrm{~m} \mathrm{~s}^{-1}$ (gray lines). White noise (blue line) with an average power of $-20 \mathrm{~dB}$ (black dashed line) is included for reference. (right) TSK-measured wave spectra $(n=456,30$-min averages) for $1<$ $\mathrm{SOG} \leq 3 \mathrm{~m} \mathrm{~s}^{-1}$ (gray lines). White noise (blue line) with an average power of $-30 \mathrm{~dB}$ (black dashed line) is included for reference.

measured mean wind speed was $U_{10}=11.6 \pm 3.8 \mathrm{~m} \mathrm{~s}^{-1}$. The mean surface current, measured using the WaMoS system, was $\left\langle U_{s}\right\rangle=0.32 \pm 0.18 \mathrm{~m} \mathrm{~s}^{-1}$.

While sampling underway, the capacity of the instruments to resolve the shorter wave scales was reduced to a degree dependent on the SOG due to aliasing [Eq. (9); Fig. 13]. For example, for the average relative SOG, $U_{r}=1.6 \mathrm{~m} \mathrm{~s}^{-1}$, and a ship heading relative to surface current direction $\left(\gamma_{r}^{\circ}\right)$ of $\left\langle\gamma_{r}\right\rangle=24^{\circ}$, the observed maximum resolution of the Riegl and TSK was reduced to $f_{c}=$ $1.7 \mathrm{~Hz}$ and $f_{c}=0.47 \mathrm{~Hz}$, respectively (Fig. 13).

Underway measurements of significant wave height from the WaMoS system were consistently lower than those provided by the Riegl (Fig. 14) by an average 7\% with a maximum difference of $18 \%$ at larger significant wave heights encountered during more energetic conditions $\left(H_{s}>5 \mathrm{~m}\right)$. The mean difference between the WaMoS and the Riegl was found to be statistically significant $(p=0.05)$. Estimates of $H_{s}$ by the Riegl and TSK show no statistical difference for $H_{s}<4 \mathrm{~m}$, although at larger significant wave heights the TSK produced higher (10\%-15\%) estimates of $H_{s}$ relative to the Riegl.

As expected, the ship-CM spectral measurements were consistently low by a factor of $1.65\left(\alpha_{m}=1.65 \pm 0.5\right)$. The $\alpha_{m}$ factor again follows from the variance of the ETFE between the ship-CM spectral response (output) and the Riegl and TSK spectral responses (input). The amplitude of the ETFE in this SOG bracket was 1.56 at $\sim 0.12 \mathrm{~Hz}$. When the ship-CM data are weighted by $\alpha_{m}$, the mean significant wave heights are within $10 \%-13 \%$ of each other under a wide range of forcing conditions (Fig. 14).

After the Doppler correction was applied, strong agreement on the spectral peak information (within $10 \%-15 \%$ ) was found among all instrumentation (see Table 2; Fig. 15). Although the noise level of the Riegl exceeds that of the TSK, the instruments show good agreement in spectral magnitude and shape relative to the WaMoS and the ship-CM (Fig. 16).

The ability of each instrument to resolve the highfrequency portion of the wave spectrum was determined by analyzing the spectral tail (Fig. 16). The Riegl underway measurements exhibited a -30 - to -20 -dB noise floor, which was attributed to white noise (likely due to high-frequency vibrations). The observed white noise explained the shallow rolloff behavior of the signal at high frequencies (Fig. 16). The signal-to-noise ratio was small at $f_{\text {int }}>1.2 \mathrm{~Hz}$; however, after accounting for noise and correcting for Doppler shift, the Riegl resolves up to 

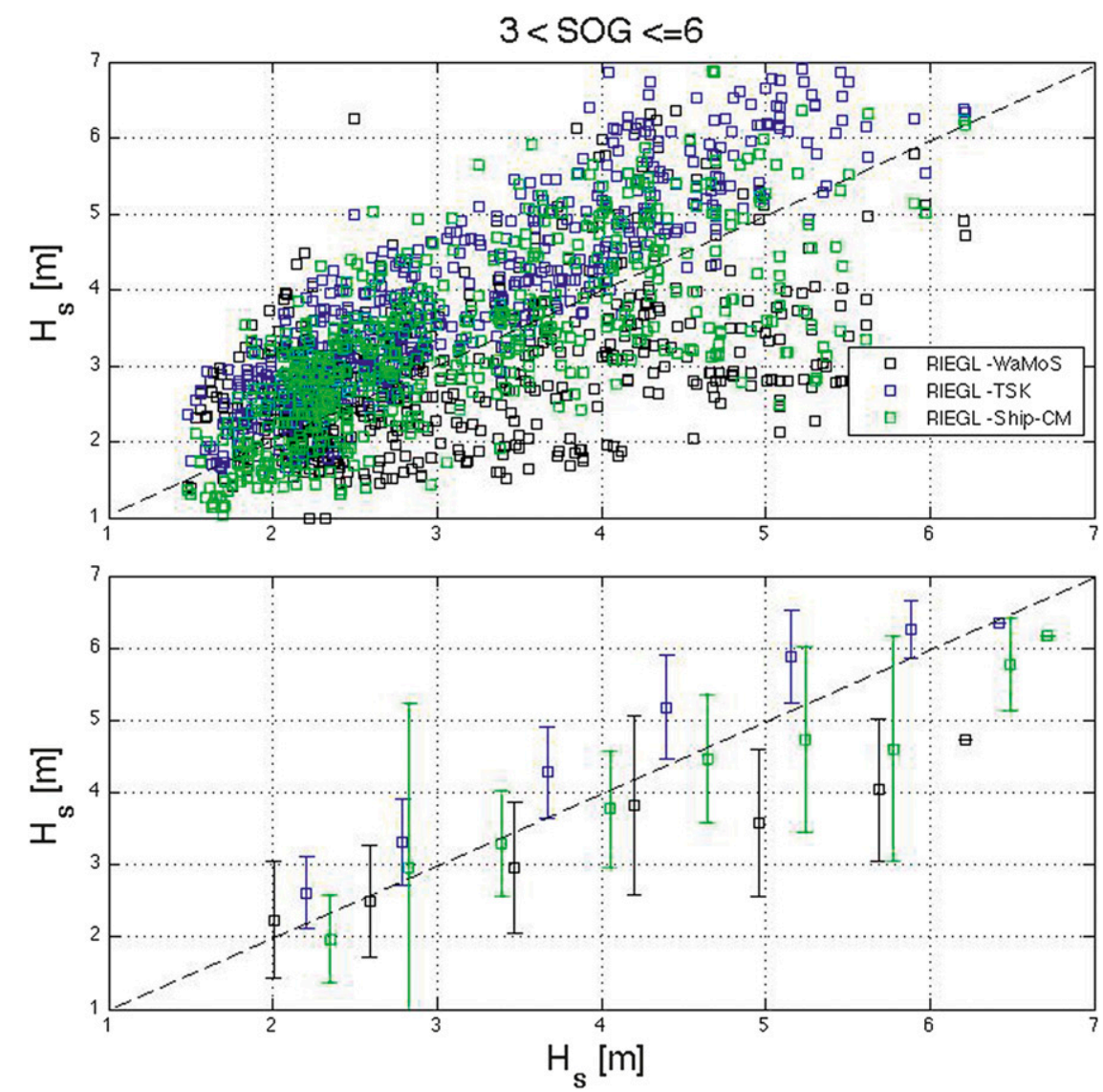

FIG. 17. (top) The 1:1 significant wave height $\left(H_{s}\right)$ comparison collected while underway at slow speeds. The $H_{s}$ estimates from the WaMoS (black squares), TSK (blue squares), and ship-CM ( $\alpha_{m}$ weighted, green squares) were plotted against Riegl data. (bottom) Bin-averaged $H_{s}$ data from the top. The Riegl-ship-CM comparison are displaced $0.3 \mathrm{~m}$ in the $x$ axis and the Riegl-TSK are displaced $0.2 \mathrm{~m}$ in the $x$ axis to aid in visualization.

$1.7 \mathrm{~Hz}$ and provides an excellent complement to the WaMoS system with a frequency rolloff of $f^{-4} \mathrm{~Hz}$ (Fig. 15). A similar noise floor was identified in the TSK data (about $-20 \mathrm{~dB}$ ). Although the TSK exhibits less variance and appears less noisy, it failed to resolve the higher frequency range of the wave spectra while underway due to a rapid spectral rolloff $\left(f^{-5}\right.$ to $\left.f^{-6}\right)$ because of aliasing while underway (Fig. 16).

\section{2) UNDERWAY: $\left(3<S O G \leq 6 M S^{-1}\right)$}

Underway measurements collected at a higher SOG $\left(\langle\mathrm{SOG}\rangle=4.4 \mathrm{~m} \mathrm{~s}^{-1}\right)$ were under oceanographic conditions similar to those collected during station keeping and slow underway measurements. Approximately $30 \%$ of the SOGasEx data were collected while SOG ranged from 3 to $6 \mathrm{~m} \mathrm{~s}^{-1}$. During data collection, the seas were predominantly old to decaying seas $\left(\left\langle U_{10} / c_{p}\right\rangle=0.6 \pm 0.2\right)$ and the mean wind speed was $U_{10}=9.2 \pm 2.8 \mathrm{~m} \mathrm{~s}^{-1}$. The mean surface current for the period was $\left\langle U_{s}\right\rangle=0.31 \pm$ $0.14 \mathrm{~m} \mathrm{~s}^{-1}$ with a relative angle $\left(\gamma_{r}=26^{\circ}\right)$. Under these conditions the maximum resolution frequencies for the Riegl and TSK are 1.2 and $0.35 \mathrm{~Hz}$, respectively.

Again, the WaMoS estimation of significant wave height was biased low by $12 \%$ relative to the Riegl. The TSK produced higher $H_{s}$ estimates by an average $15 \%$ across the sampled conditions relative to the Riegl. Similarly, the ship-CM measurements of $H_{s}$ m were biased low (Fig. 17). The weighting factor $\left(\alpha_{m}\right)$ from the variance of the ETFE was higher, $\alpha_{m}=1.8 \pm 0.5$, than previous estimates and exhibited a larger uncertainty (Fig. 17). The amplitude of the ETFE in this SOG bracket was 2.1 at $\sim 0.16 \mathrm{~Hz}$. When the ship-CM data are weighted by $\alpha_{m}$, the mean significant wave heights from the ship-CM estimates are $10 \%-12 \%$ larger than the Riegl estimates (Fig. 17).

Underway measurements collected at a higher SOG produced the largest discrepancies between the measured spectral peaks (up to $25 \%$ for the TSK - WaMoS). Here, the spectral peak retrieved using the WaMoS system, $f_{p}=$ $0.096 \pm 0.016 \mathrm{~Hz}$, served as the reference measurement 

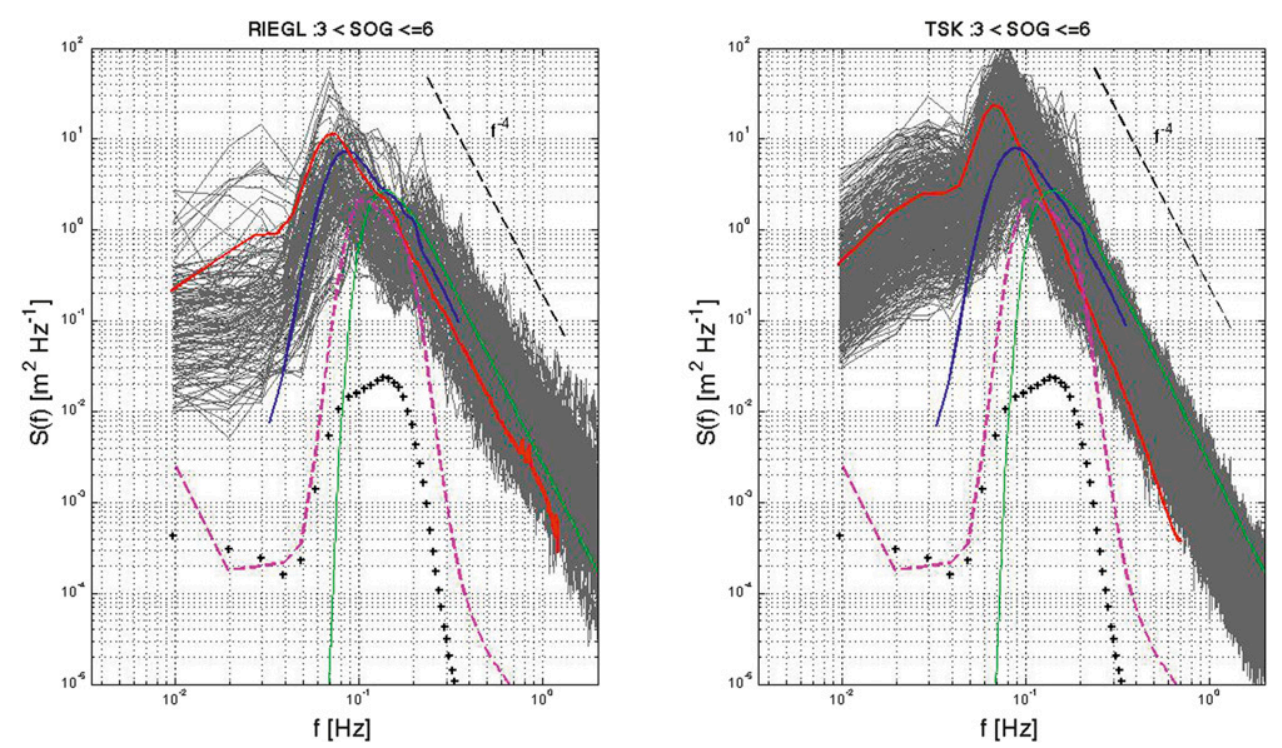

FIG. 18. Average wave frequency spectra measured using the Riegl (red line) and TSK (red line) compared to the WaMoS (blue line) and ship-CM (dashed magenta line) wave spectra collected while underway at slow speeds $\left(3<\mathrm{SOG} \leq 6 \mathrm{~m} \mathrm{~s}^{-1}\right)$. The Donelan et al. (1985) spectral parameterization (mean $U_{10}=9.2 \mathrm{~m} \mathrm{~s}^{-1}$; green line), the frequency slope of $f^{-4} \mathrm{~Hz}$ (black dashed line), and the ghost wave field from added pitch (black pluses) are included for reference. (left) Riegl-measured spectral realizations ( $n=135,30$-min averages) for $3<\mathrm{SOG} \leq 6 \mathrm{~m} \mathrm{~s}^{-1}$ (gray lines). (right) TSK-measured spectral realizations ( $n=135,30$-min averages) for $3<\mathrm{SOG} \leq 6 \mathrm{~m} \mathrm{~s}^{-1}$ (gray lines).

due to the implicit directional Doppler correction. Compared to the WaMoS, both the Riegl $\left(f_{p}=0.074 \pm\right.$ $0.04 \mathrm{~Hz})$ and TSK $\left(f_{p}=0.070 \pm 0.02 \mathrm{~Hz}\right)$ placed the spectral peak at a lower frequency for a larger SOG (Table 2; Fig. 18). The noise floor of the Riegl and TSK remained the same for higher cruising speeds (about $-30 \mathrm{~dB}$ ). High-frequency noise for the TSK was irrelevant because the measurements only extended to $0.35 \mathrm{~Hz}$ due to aliasing at high cruising speeds (Fig. 19). After Doppler correction, the spectral tails showed the same behavior as the underway measurements collected during slow cruising speeds. Even though the spectra tail experienced a reduction in the maximum resolution, the shape was not distorted and the same characteristic frequency slopes were observed for the Riegl and TSK. As was true for the underway measurements collected at slow speeds, the TSK tail showed a steep rolloff, $f^{-5}$ to $f^{-6}$, relative to the $f^{-4}$. The faster rolloff of the TSK was again associated with aliasing issues leading to a reduced capacity to resolve wave scales of frequencies larger than $0.35 \mathrm{~Hz}$ (Fig. 19).

\section{Discussion}

A comprehensive instrument intercomparison exercise and the application of effective motion correction schemes, completed using data collected during
SOGasEx, resulted in the full 1D frequency wave spectrum for SOG $\leq 3 \mathrm{~m} \mathrm{~s}^{-1}$, with the best resolved spectra collected while station keeping. Only added white noise limited the high-frequency resolution of all deployed instrumentation during station keeping. The Edson et al. (1998) motion correction algorithm effectively accounted for any motion contamination for SOG $<3 \mathrm{~m} \mathrm{~s}^{-1}$. At $\mathrm{SOG} \geq 3 \mathrm{~m} \mathrm{~s}^{-1}$, wave spectral measurements deteriorated precipitously; however, some wave field statistics could still be gleaned from the WaMoS, Riegl, and ship-CM within a frequency range of 0.035 to $1.2 \mathrm{~Hz}$.

Mean significant wave height measurements obtained using the WaMoS, Riegl, and TSK were within $10 \%-$ $15 \%$ for SOG $\leq 6 \mathrm{~m} \mathrm{~s}^{-1}$ and $1<H_{s}<4 \mathrm{~m}$. WaMoS estimates of $H_{s}$ were consistently biased low relative to the Riegl and TSK, particularly during severe sea conditions. The ship-CM provided accurate mean significant wave height information for SOG $\leq 6 \mathrm{~m} \mathrm{~s}^{-1}$ and $1<H_{s}<4 \mathrm{~m}$ when the amplitude and variance of the ETFE, which increase with SOG, were taken into account. WaMos, which has the capacity to provide directional wave spectra, is an ideal instrument to deploy during moderate to rough sea conditions $\left(H_{s}<4 \mathrm{~m}\right)$. However, The WaMoS system consistently underestimates significant wave height; therefore, it should be deployed with an IMU package(s) or a laser altimeter to provide adequate 

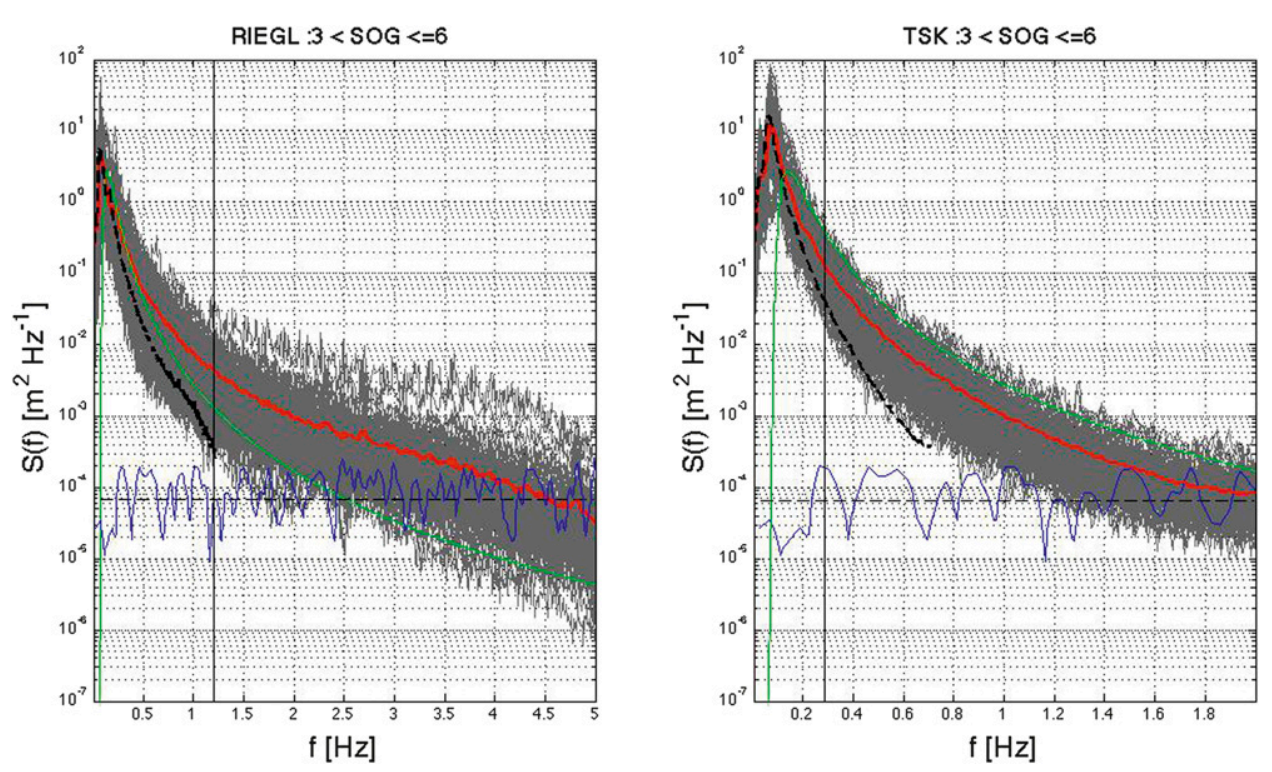

FIG. 19. Average spectral tail measurements collected while underway at relatively high speed $(3<$ SOG $\leq 6 \mathrm{~m} \mathrm{~s}^{-1}$ ) using the Riegl (red line) and the TSK (red line) were compared to the Donelan et al. (1985) spectral parameterization (mean $U_{10}=11.6 \mathrm{~m} \mathrm{~s}^{-1}$; green line). White noise (blue line) with an average power of $-20 \mathrm{~dB}$ (black dashed line) is included for reference. The reduction in each instrument's maximum frequency resolution, defined as the high-frequency cutoff, is included (black solid line). Average spectral tail measurements after Doppler correction and accounting for aliasing are included for both instruments (black dashed line). (left) Riegl-measured wave spectra $(n=456,30$-min averages) for $3<\mathrm{SOG} \leq 6 \mathrm{~m} \mathrm{~s}^{-1}$ (gray lines). (right) TSK-measured wave spectra $(n=456,30$-min averages) for $3<\mathrm{SOG} \leq 6 \mathrm{~m} \mathrm{~s}^{-1}$ (gray lines).

data correction and validation. During rough sea conditions $\left(H_{s}>4 \mathrm{~m}\right)$, a combined IMU-Riegl system would provide the most robust estimates of $H_{s}$.

Highly accurate spectral shape, including the spectral peak and the high-frequency (tail) portions of the spectra, were retrieved during SOG $\leq 3 \mathrm{~m} \mathrm{~s}^{-1}$. The spectral tail was best captured by the Riegl, consistently exhibiting an $f^{-4}$ frequency rolloff. For the Riegl, the noise from highfrequency vibrations and aliasing effects were the chief factors limiting its resolution. Aliasing not only affected the Riegl but severely limited the TSK when cruising into the wave field at high speeds. In general, spectral peak misalignment and shape degradation were observed for SOG $>3 \mathrm{~m} \mathrm{~s}^{-1}$.

Across the range of observations the potential for added motion contamination due to the unremoved instrument tilt, assessed using the ghost wave model, was found to be a nonissue. For a ship in motion, however, Doppler shift corrections are essential. A 1D Doppler shift correction proved to be effective here; however, for a more confused wave field (i.e., more variability in wave direction), accounting for directionality is suggested. The deployment of IMUs was used to calculate the ETFE and estimate the MTF amplitude of the R/V Ronald H. Brown. The amplitude and frequency of the ETFE were used to weight the ship-CM $H_{s}$ estimates and explore the ship-as-buoy analogy.

While station keeping and underway at slow speeds $\left(\mathrm{SOG} \leq 3 \mathrm{~m} \mathrm{~s}^{-1}\right.$ ), the WaMoS-Riegl systems together provide the highest resolved full 1D wave spectra extending from the low-frequency $(0.035-0.35 \mathrm{~Hz})$ to highfrequency $(0.35-1.5 \mathrm{~Hz})$ range. Together, the WaMoS and Riegl can be used to validate one another (using their overlapping frequency range) and WaMoS provides added value with directional wave information. Under similar conditions, the TSK also provides a good midfrequency compliment to WaMoS. Even though the upper limit of the TSK is $0.5 \mathrm{~Hz}$, less variance in the TSK data was observed.

\section{Conclusions}

Application of essential motion correction routines, including the Edson et al. (1998) motion correction algorithm and the Doppler shift correction, and accounting for aliasing produces the highest resolved 1D wave spectrum data. Data acquisition using accelerometers is a key part of this process. During station keeping or slow underway sampling speeds ( $\mathrm{SOG} \leq 3 \mathrm{~m} \mathrm{~s}^{-1}$ ), the WaMos and Riegl together provided the highest resolved, full 1D 
wave spectra $(0.035-1.5 \mathrm{~Hz})$ and highly accurate measurements of significant wave height during moderate to rough sea conditions $\left(H_{s}<4 \mathrm{~m}\right)$. During rough sea conditions $\left(H_{s}>4 \mathrm{~m}\right)$, a combined Riegl-IMU system would provide the most robust estimates of $H_{s}$. At high underway speeds (SOG $>3 \mathrm{~m} \mathrm{~s}^{-1}$ ) spectral information could still be gleaned from the WaMoS, Riegl, and ship-CM within a limited frequency range of 0.035 to $1.2 \mathrm{~Hz}$. Spectral shape information, including the spectral peak and tail, are only accurate when retrieved during SOG $\leq 3 \mathrm{~m} \mathrm{~s}^{-1}$.

Acknowledgments. The National Science Foundation (Grant 0647475), National Oceanic and Atmospheric Administration (NA07OAR4310084), and the NOAA Office of Climate Observations supported the work presented here. Additional support was provided by the National Science Foundation (0647667; Christopher Zappa) and the Center for Environmental Sciences and Engineering (CESE) at the University of Connecticut (2011; Cifuentes-Lorenzen). Finally, we would like to thank the reviewers for their commitment to helping us produce a much improved manuscript.

\section{REFERENCES}

Dankert, H., and W. Rosenthal, 2004: Ocean surface determination from X-band radar-image sequences. J. Geophys. Res., 109, C04016, doi:10.1029/2003JC002130.

Donelan, M., J. Hamilton, and W. Hui, 1985: Directional spectra of wind-generated waves. Philos. Trans. Roy. Soc. London, A315, 509-562.

Edson, J. B., A. A. Hinton, K. E. Prada, J. E. Hare, and C. W. Fairall, 1998: Direct covariance flux estimates from mobile platforms at sea. J. Atmos. Oceanic Technol., 15, 547-562.

— sea transfer experiment in low winds. Bull. Amer. Meteor. Soc., 88, 341-356.

- , and Coauthors, 2011: Direct covariance measurement of $\mathrm{CO}_{2}$ gas transfer velocity during the 2008 Southern Ocean gas exchange experiment: Wind speed dependency. J. Geophys. Res., 116, C00F10, doi:10.1029/2011JC007022.

Fairall, C. W., E. F. Bradley, D. P. Rogers, J. B. Edson, and G. Young, 1996: Bulk parameterization of air-sea fluxes for tropical ocean-global atmosphere coupled-ocean atmosphere response experiment. J. Geophys. Res., 101 (C2), 3747-3764.
Hanson, K. A., T. Hara, E. J. Bock, and A. B. Karachintsev, 1997: Estimation of directional surface wave spectra from a towed research catamaran. J. Atmos. Oceanic Technol., 14, 1467-1482.

Ho, D. T., and Coauthors, 2011: Southern Ocean gas exchange experiment: Setting the stage. J. Geophys. Res., 116, C00F08, doi:10.1029/2010JC006852.

Hwang, P. A., D. W. Wang, E. J. Walsh, W. B. Krabill, and R. N. Swift, 2000: Airborne measurements of the wavenumber spectra of ocean surface waves. Part I: Spectral slope and dimensionless spectral coefficient. J. Phys. Oceanogr., 30, 2753-2767.

Irish, J. L., J. M. Wozencraft, A. G. Cunningham, and C. Giroud, 2006: Nonintrusive measurement of ocean waves: Lidar wave gauge. J. Atmos. Oceanic Technol., 23, 1559-1572.

Miller, S. D., T. S. Hristov, J. B. Edson, and C. A. Friehe, 2008: Platform motion effects on measurements of turbulence and air-sea exchange over the open ocean. J. Atmos. Oceanic Technol., 25, 1683-1694.

Nielsen, U. D., 2006: Estimations of on-site directional wave spectra from measured ship responses. Mar. Struct., 19, 33-69.

Nieto Borge, J. C., and C. G. Soares, 2000: Analysis of directional wave fields using x-band navigation radar. Coastal Eng., 40, 375-391.

_ a wave monitoring instrument. Coastal Eng., 37, 331-342.

— G. Rodriguez, K. Hessner, and P. Gonzalez, 2004: Inversion of marine radar images for surface wave analysis. J. Atmos. Oceanic Technol., 21, 1291-1300.

Reichert, K., K. Hessner, J. C. Nieto Borge, and J. Dittmer, 1999: WaMoS II: A radar based wave and current monitoring system. Proc. Ninth Int. Offshore and Polar Engineering Conf., International Society of Offshore and Polar Engineers, Brest, France, 139-143.

Serafino, F., C. Lugni, and F. Soldovieri, 2010: A novel strategy for the surface current determination from marine X-band radar data. IEEE Geosci. Remote Sens. Lett., 7, 231-235, doi:10.1109/LGRS.2009.2031878.

Stredulinsky, D., and E. Thornhill, 2011: Shipboard wave measurement through fusion of wave radar and ship motion data. J. Ship Res., 55, 73-85.

Sun, J., and Coauthors, 2005: Measurement of directional wave spectra using aircraft laser altimeters. J. Atmos. Oceanic Technol., 22, 869-885.

Tannuri, E., J. Sparano, A. Simos, and J. Da Cruz, 2003: Estimating directional wave spectrum based on stationary ship motion measurements. Appl. Ocean Res., 5, 243-261.

Thornhill, E., and D. Stredulinsky, 2010: Real time local sea state measurement using wave radar and ship motions. Trans. Soc. Nav. Archit. Mar. Eng., 118, 248-259.

Toshio, I., and T. Daisuke, 2002: Bayesian estimation of directional wave spectra for ship guidance system. Int. J. Offshore Polar Eng., 12, 25-30. 